\title{
Modelling Ambient Vibration Responses Induced by Operation of Metro Train on Curved Rail Segment with Small Curvature Radius
}

\author{
Bo Pan $\mathbb{D}^{1},{ }^{1}$ Wei Zhang ${ }^{10},{ }^{1}$ Shuai Zheng, ${ }^{2}$ Ming-liang Zhou, ${ }^{3}$ Chun-fa Zhao, ${ }^{4}$ \\ and Billie F. Spencer $\mathrm{Jr}^{5}$ \\ ${ }^{1}$ School of Earth Sciences and Engineering, Nanjing University, Nanjing 210023, China \\ ${ }^{2}$ China Railway Shanghai Group Co., Ltd., Shanghai 200071, China \\ ${ }^{3}$ College of Civil Engineering, Tongji University, Shanghai 200092, China \\ ${ }^{4}$ Traction Power State Key Laboratory, Southwest Jiaotong University, Chengdu 610031, China \\ ${ }^{5}$ Department of Civil and Environmental Engineering, University of Illinois at Urbana-Champion, Urbana, IL 61801, USA \\ Correspondence should be addressed to Wei Zhang; wzhang@nju.edu.cn
}

Received 8 October 2019; Revised 29 December 2019; Accepted 22 January 2020; Published 22 February 2020

Academic Editor: Francesco Clementi

Copyright (c) 2020 Bo Pan et al. This is an open access article distributed under the Creative Commons Attribution License, which permits unrestricted use, distribution, and reproduction in any medium, provided the original work is properly cited.

\begin{abstract}
The torsional effect of the tracks on curved segment intensifies the ambient vibration response induced by Metro operation. This paper studies the ambient vibration responses induced by the operation of the Metro train on curved rail segments. By taking the curved segment of Hangzhou Metro Line 1 of China as an example, the wheel-rail model employing the multibody dynamics is demonstrated; the dynamic wheel-rail force of a B-type vehicle passing through a $350 \mathrm{~m}$ radius curved segment is also calculated. A finite element method model of the track-tunnel-soil-building is developed and verified by comparing the measured results with the simulated ones. Then, we analyzed the ambient vibration responses induced by the Metro operation. The results show that the horizontal vibration induced by the Metro train, on curved segments, cannot be ignored. When propagating on the ground, the variation trend of the horizontal vibration acceleration is greater than that of the vertical vibration. The horizontal vibration attenuates faster than the vertical vibration. The secondary vibration along the horizontal direction yields a significant amplifying effect upon the building. The vibration level increases with the height of the building, along the horizontal direction, but the vertical vibration level changes negligibly. The insight exhibits the influence level of the horizontal action of the Metro train wheels to the tracks, which can be referred by the practitioners for the planning and operation.
\end{abstract}

\section{Introduction}

For the past several decades, urban rail transit has boomed in developing countries, such as China [1]. Metro can greatly relieve the pressure of the urban traffic; however, the Metro train-induced structural vibration, along with the ambient noise, can also cause adverse effects on humans, including physical, physiological, and psychological effects [2-7]. Therefore, ambient vibration along Metro lines has already begun to gain increasing attention.

To analyze the ambient vibration response, obtaining the train vibration load is one of the most important steps; many scholars have done a variety of studies in this area by developing theoretical models or field test methods. As is known, Timoshenko [8] solved the classical problem of the rail dynamic stress based on the elastic foundation beam model, which is the basis of the research in this area. Auersch [9] established the vehicle-track interaction model and obtained the wheel-rail excitation force of the train. Field measurement and numerical simulation are both needed to analyze these specific engineering problems. Shao et al. [10] carried out numerical simulation by employing the multibody dynamics, compared with physical experiments to verify the effectiveness of their approach. Sheng et al. [11] put forward the coupling analysis method of the finite element and boundary element and obtained the dynamic response solution of the train vibration. Wolf [12] used the finite difference method software, FLAC ${ }^{3 \mathrm{D}}$, to obtain the 
ground displacement variations under the Metro load and compared them with the measured values. Hussein et al. [13] exhibited the PiP model for attaining the vibration response from railway tunnel in a multilayered half-space.

In addition, a good number of the former studies focused on the propagation and attenuation laws of the ground vibration induced by the Metro operations. Sheng et al. [14] analyzed the attenuation law of the ground vibration intensity by employing a layered half-space model of the Metro. Yang and Hsu [15] found that the ground vibration caused by the Metro has an amplification zone in the attenuation process. Volberg [16] studied the propagation law and attenuation characteristics of the ground vibration and discovered that the surface wave plays a dominant role in the vehicle-induced vibration. Hayakawa et al. [17] studied the mechanism of the vibration induced by Metro train and the propagation law of the elastic wave on the ground and presented a prediction method of the surrounding environmental vibration caused by the Metro operation. Melke and Kraemer [18] found that when the vibration frequency of the Metro train in operation approaches the inherent frequency of the surrounding soils, the acceleration of the ground surface has a significant increase due to the resonance.

The vibration response of the buildings, caused by the Metro train in operation, has also been broadly studied. Based on the impulse excitation and experimental analysis, Melke and Kramer [19] studied the vibration response of the adjacent buildings around Metro lines. Xia et al. [20] found that the vibration level of the building floors increased with the train speed and decreased with the distance away from the railway; moreover, the vibration in high-rise buildings is stronger than that of the low-rise buildings. Okumura and Kuno [21] studied the influence of the vibration caused by the high-speed train operation on the surrounding buildings, discovering the main influence factors which include the track centerline, train speed, and length of the train.

Note that more and more Metro lines with curved segments have been developed in big cities, especially in China. However, so far, limited studies have focused on the ambient vibration response caused by the trains running on curved segments. Former investigations suggest that the horizontal vibration of the train traveling on the curved segment might enhance the amplitude of the ambient response [22]; such case could be intensified when the curve radius is small, generally meaning less than $650 \mathrm{~m} \mathrm{[23].}$ However, to what extent the amplification effect can reach still needs to be further studied.

In this paper, taking a curved segment of Hangzhou Metro Line 1 of China as an example, we demonstrated a wheel-rail model by employing the multibody dynamics method, obtaining the dynamic wheel-rail force of the B-type vehicle passing through a curved segment with a radius of $350 \mathrm{~m}$. Subsequently, the FEM model of the tracktunnel-soil is developed. After validating the model by comparing with the measured results, the ambient vibration response, including the building vibration response, induced by Metro trains on the curved segment with a small radius, is analyzed. The investigation may enhance our understanding of the vibration responses caused by the Metro operation on curved segments.

\section{Methodology}

2.1. Mathematical Equations of the Wheel-Rail Creep Force. The model analysis method is a method to calculate the wheel-rail creep force of the train by using the finite element software, simulation software, and so on. It is based on the wheel-rail coupling dynamics. The system model mainly consists of vehicle system, track system, and wheel-rail model, as shown in Figure 1.

The vibration behavior of a Metro train on a curved segment is more complicated than that on a straight segment because of the side wear and wave wear $[25,26]$.

When a train moves on a straight-line segment, the horizontal effect of the track on the train is usually neglected. The vertical wheel-rail force can be determined by Hertzian nonlinear elastic contact theory equations [27] as follows:

$$
P=\left[\frac{1}{G} \cdot \delta \cdot Z\right]^{3 / 2},
$$

where $G$ is the contact rail constant and $\delta \cdot Z$ is the wheelrail elastic compression.

When a train runs on a curved segment, the wheels collide with the track surface, owing to the irregularity of the track and centrifugal force, which results in the wheel-rail contact force. The action point is at the wheel-rail contact, as shown in Figures 2(a) and 2(b).

As seen from Figure 2(b), the wheel-rail vertical force $P$ can be regarded as the vertical component of the wheel-rail normal force $K$ and creep force $Q$, while the wheel-rail horizontal contact force $W$ can be regarded as the combination of the horizontal component of $K$ and $Q$, as follows:

$$
\begin{gathered}
P=K p+Q p, \\
W=K w+Q w,
\end{gathered}
$$

where $K(p)$ and $K(w)$ are the vertical and horizontal component of the wheel-rail normal force $K$, respectively, and $Q(p)$ and $Q(w)$ are the vertical and horizontal component of the creep force $Q$, respectively.

The wheel-rail creep force $Q$ is related to the vertical, horizontal, and torsional accelerations of the left and right wheel-rail pairs. The corresponding formula yields

$$
Q=Q[L(v), R(v)]
$$

where $L(v)$ and $R(v)$ are the vibration speed related to the left and right rail.

2.2. Vibration Level Formula. Herein, we use the vibration level to describe the variation range of the vibration magnitude of the Metro vibration. The formula for the vibration acceleration level [28] yields 


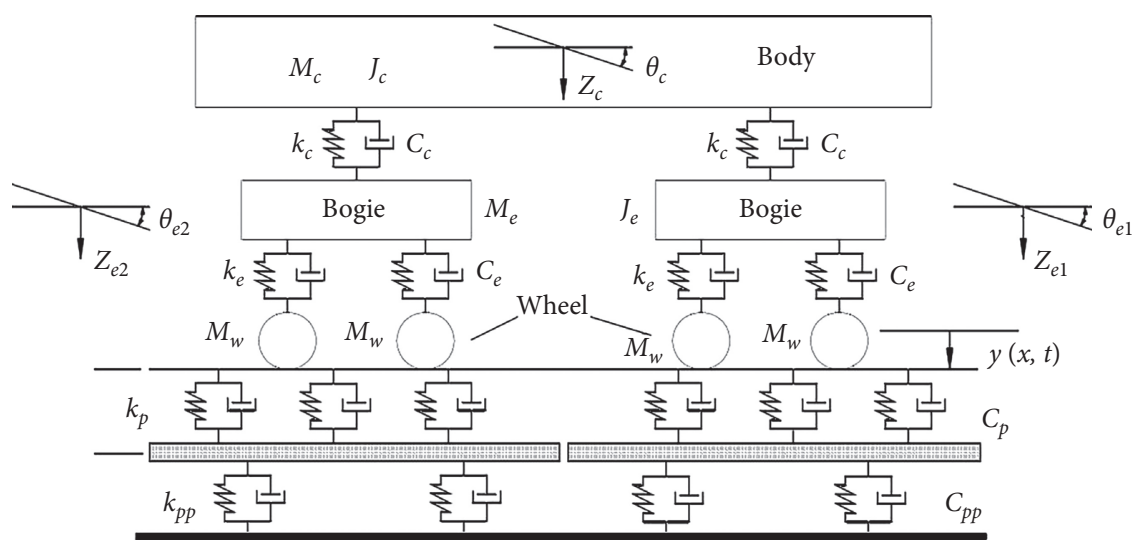

Figure 1: Train-track dynamic analysis model [24].

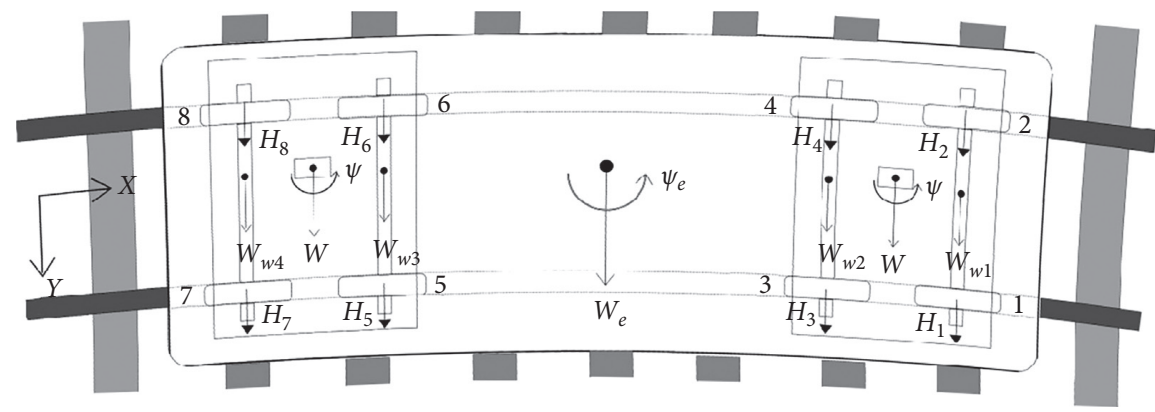

(a)

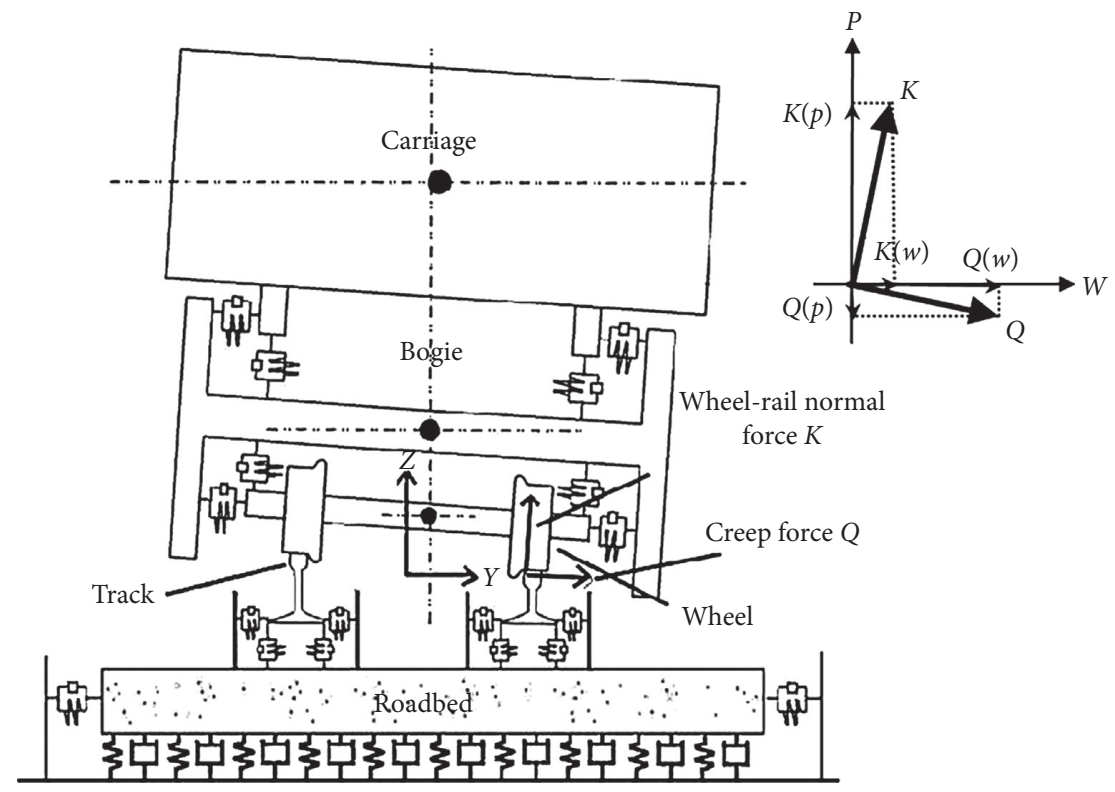

(b)

FIgURE 2: Wheel-rail coupling model: (a) top view; (b) rear view.

$$
V_{l}=20 \lg \frac{a_{\omega}}{a_{0}}
$$

where $a_{0}$ is the reference acceleration. Typically, $a_{0}=10^{-6} \mathrm{~m} / \mathrm{s}^{2}$. $a_{w}$ is the acceleration effective value, also known as the acceleration root mean square value. The formula yields

$$
a_{w}=\left[\frac{1}{T} \int_{0}^{T} a_{w}^{2}(t) \mathrm{d} t\right]^{1 / 2}
$$




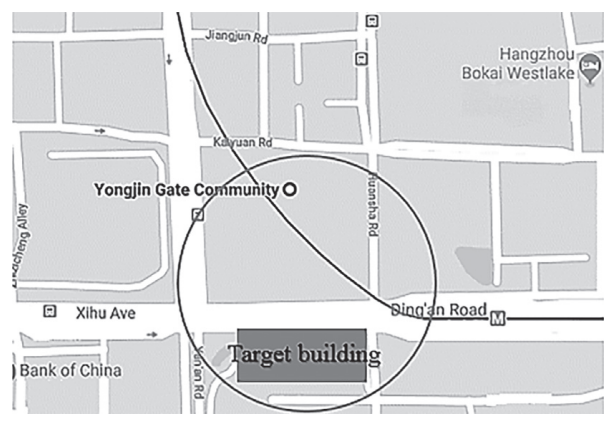

Figure 3: A curved segment of Hangzhou Metro Line 1.

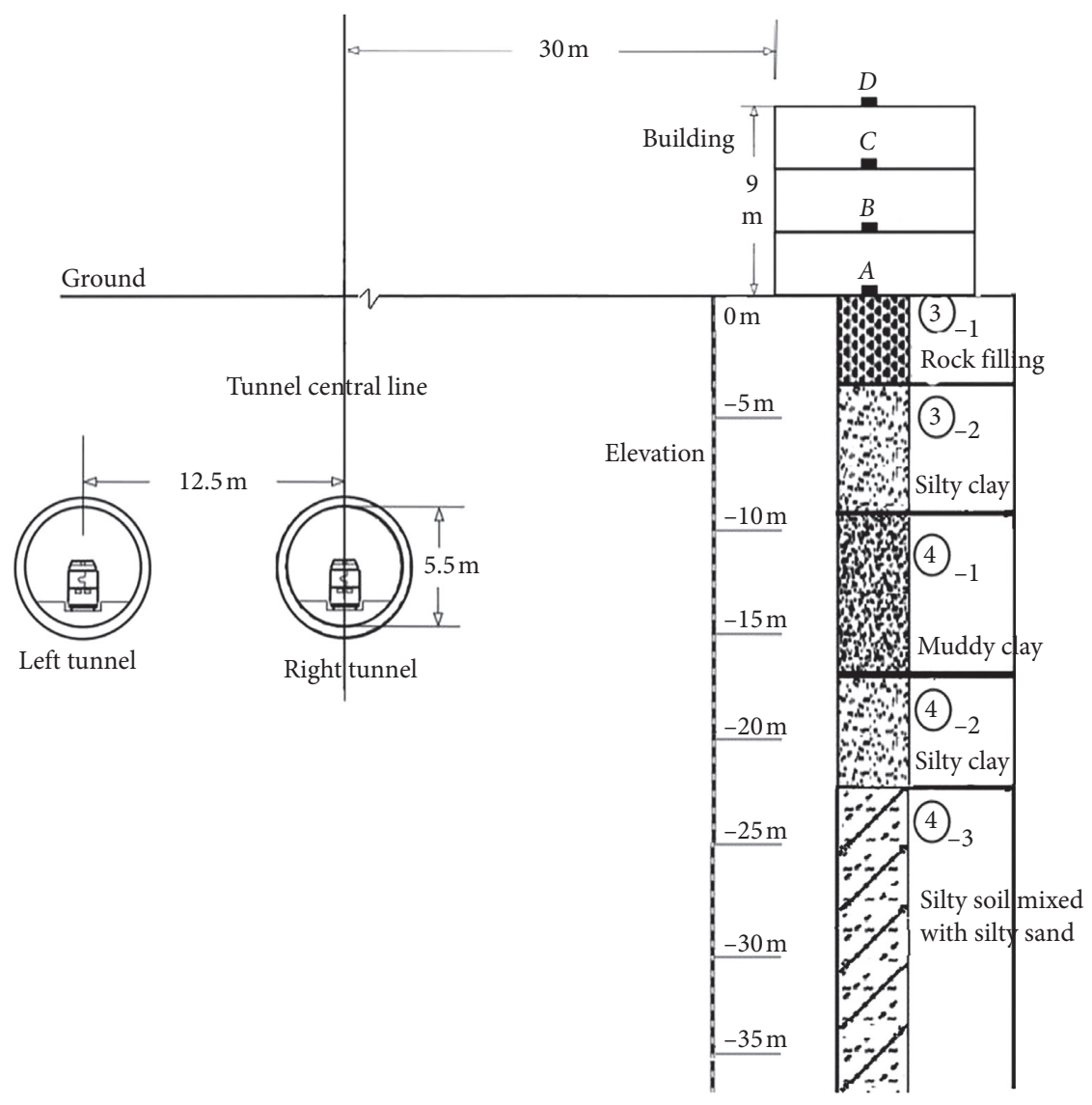

Figure 4: Profile of the soil types beneath the tunnel.

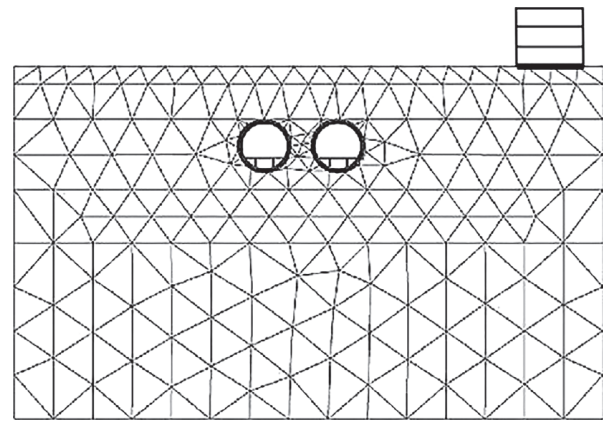

FIGURE 5: FEM model of the track-tunnel-soil-building. 
TABLe 1: Parameters of the building material.

\begin{tabular}{lcccc}
\hline Material & EA $\left(\mathrm{kN} / \mathrm{m}^{2}\right)$ & EI $\left(\mathrm{kN} / \mathrm{m}^{2}\right)$ & Poisson ratio & Weight $\left(\mathrm{kN} / \mathrm{m}^{3}\right)$ \\
\hline Floor & $3.00 E 8$ & $2.50 E 5$ & 0.2 & 25 \\
Wall & $6.60 E 6$ & $4.95 E 4$ & 0.1 & 20 \\
\hline
\end{tabular}

Table 2: Parameters of soil layers and the tunnel.

\begin{tabular}{|c|c|c|c|c|c|c|}
\hline Soil layers & $\begin{array}{l}\text { Layer thickness } \\
(\mathrm{m})\end{array}$ & $\begin{array}{l}\text { Young modulus } \\
(\mathrm{MPa})\end{array}$ & $\begin{array}{l}\text { Poisson } \\
\text { ratio }\end{array}$ & $\begin{array}{c}\text { Saturated unit weight } \\
\left(\mathrm{kN} / \mathrm{m}^{3}\right)\end{array}$ & $\begin{array}{c}\text { Internal friction } \\
\text { angle } \varphi\left({ }^{\circ}\right)\end{array}$ & $\begin{array}{c}\text { Cohesive force } C \\
(\mathrm{kpa})\end{array}$ \\
\hline (3)-1 rock-filling & 3 & 20 & 0.30 & 19.9 & 12 & 25.3 \\
\hline (3) -2 silty clay & 6 & 17 & 0.30 & 19.3 & 18 & 27.2 \\
\hline (4) -1 muddy clay & 7.5 & 13.5 & 0.30 & 18.8 & 8 & 17.5 \\
\hline (4) -2 silty clay & 5 & 15 & 0.30 & 18.9 & 19 & 26.0 \\
\hline $\begin{array}{l}\text { (4)- } 3 \text { silty soil mixed } \\
\text { with silty sand }\end{array}$ & 38.5 & 40 & 0.30 & 19.6 & 30 & 11.6 \\
\hline Tunnel lining & - & 35000 & 0.20 & 28 & - & - \\
\hline Tunnel track bed & - & 20000 & 0.20 & 21 & - & - \\
\hline
\end{tabular}

where $a_{w}(t)$ is the acceleration time history and $T$ is the measurement duration.

\section{Case Study}

3.1. Engineering Background. Hangzhou Metro Line 1 is located in Hangzhou City, Zhejiang Province, China. The Metro line starts from Xianghu Station in the Xiaoshan District and passes through Qiantang River and the commercial district and terminates at the Xiasha Riverside Station in Yuhang District. The total distance of the rail line is $61.434 \mathrm{~km}$, of which the underground segment comprises $41.36 \mathrm{~km}$, and the length of the curved segment accounts for $13.1 \%$ of the total distance. Among them, the curved segment of Yan'an Road between Longxiangqiao Station and Anding Road Station passes through residential areas. The target building near the curve segment is $30 \mathrm{~m}$ away from the centerline of the right tunnel, $10 \mathrm{~m}$ wide, and $3 \mathrm{~m}$ high for each floor. As shown in Figure 3, the plane radius of the line is $350 \mathrm{~m}$, the inner diameter of the Metro tunnel $5.5 \mathrm{~m}$, the distance between the two tunnels $12.5 \mathrm{~m}$, and the speed of the Metro $60 \mathrm{~km} / \mathrm{h}$. The elastic short sleeper integral ballast bed is adopted. The soil layers mainly consist of the filling soil, silty clay, and silty sand.

3.2. FEM Model. The two-dimensional FEM model of the track-tunnel-soil-building is developed by PLAXIS software. The theory of the dynamic module analysis in PLAXIS software is based on linear elastic model, so all constitutive models in the software can be used for dynamic analysis. The model is located in perpendicular to the track and tunnel. The horizontal distance of the model is $100 \mathrm{~m}$ and the height is $60 \mathrm{~m}$. For efficiency, the complex soil layers are simplified to five soil layers, including the rockfilling, silty clay, muddy clay, silty clay, and silty soil mixed with silty sand. The Mohr-Coulomb constitutive model is adopted, and the damping ratio is set as 0.03 . On the left and right boundaries of the model, the horizontal direction does not allow the displacement occurrence, whereas the
TABle 3: Fastener parameters.

\begin{tabular}{|c|c|c|}
\hline \multicolumn{2}{|l|}{ Fastener type } & DTVI2-1 \\
\hline \multicolumn{2}{|l|}{ Classification } & Elastic separation \\
\hline \multicolumn{2}{|c|}{ Suitable range } & Rail tunnel for $60 \mathrm{~kg} / \mathrm{m}$ \\
\hline \multicolumn{2}{|c|}{$\begin{array}{l}\text { Pullout resistance of embedded } \\
\text { parts }\end{array}$} & Not less than $60 \mathrm{kN}$ \\
\hline \multirow{4}{*}{ Spring strip } & Type & DI spring strip $(\varphi 18)$ \\
\hline & Clamping force & $8.25 \mathrm{kN}$ \\
\hline & Elastic dista & $10.5 \mathrm{~mm}$ \\
\hline & Tightening torque & - \\
\hline \multirow{3}{*}{\multicolumn{2}{|c|}{$\begin{array}{l}\text { Static stiffness of the elastic cushion } \\
\text { Gauge adjustment } \\
\text { Horizontal adjustment }\end{array}$}} & $20-40 \mathrm{kN} / \mathrm{mm}$ \\
\hline & & $+8,-12 \mathrm{~mm}$ \\
\hline & & $30 \mathrm{~mm}$ \\
\hline
\end{tabular}

vertical direction permits the deformation occurrence. To avoid the reflection of the elastic waves, viscous absorption boundaries are set on the left, right, and lower sides of the model. A neighbor four-floored building is additionally developed to analyze the ambient vibration response, as shown in Figure 4. The building is $30 \mathrm{~m}$ away from the centerline of the right tunnel, $10 \mathrm{~m}$ wide, and $3 \mathrm{~m}$ high for each floor. The building is a frame structure with isotropic plate elements for walls and floor. The foundation of the building is independent foundation, which is simplified as plate element in the model. Rayleigh damping is used for material damping, in which Rayleigh $\alpha$ and Rayleigh $\beta$ are 0.128 and 0.007 , respectively. The strength grade of underground rail concrete is $\mathrm{C} 30$; the strength grade of ground rail concrete is C40. Double-layer reinforcements and longitudinal reinforcements adopt $\varphi 14 \mathrm{HRB} 335$ threaded reinforcements. The stirrup uses $\varphi 10 \mathrm{HPB} 235$ plain round reinforcement, and $\varphi 10 \mathrm{HPB} 235$ frame reinforcements are set between the two layers of the reinforcements. The rail adopts DTVI2-1 type fastener. The sleeper dimensions are $220 \mathrm{~mm}$ in width, $160 \mathrm{~mm}$ in thickness, and $2500 \mathrm{~mm}$ in length. The sleepers have larger resistance and rigidity in the transverse and longitudinal directions, smoother disturbance at the rail bottom, and smaller dynamic gradient. The sleepers have high elastic 
TABle 4: Vehicle parameters.

\begin{tabular}{|c|c|c|c|}
\hline Parameters & Value $(\mathrm{mm})$ & Parameters & $\begin{array}{l}\text { Value } \\
(\mathrm{mm})\end{array}$ \\
\hline Metro body length & 19,000 & Vehicle distance & 12600 \\
\hline Vehicle length (trailer car/m) & $20450 / 19520$ & Fixed wheelbase & 2300 \\
\hline Body width (floor area) & 2800 & Vehicle weight center height & 1800 \\
\hline Body height (when bowing down) & $\leq 3810$ & Longitudinal spacing of the axial springs & 550 \\
\hline Inside net height & $\geq 2100$ & Transverse shock absorber height & 697 \\
\hline Floor height & 1100 & Transverse stop height & 465 \\
\hline Coupler height & 720 & Lateral stop clearance & 25 \\
\hline Bogie center distance & 12600 & Wheel rolling diameter & 840 \\
\hline Bogie wheelbase & 2300 & Rolling circle span & 1493 \\
\hline $\begin{array}{l}\text { Wheel diameter (new wheel)/ } \\
\text { (semiabrasion)/(abrasion) }\end{array}$ & $\begin{array}{l}\Phi 840 / \Phi 805 / \\
\Phi 770\end{array}$ & $\begin{array}{c}\text { Transverse spacing of primary suspension spring/lateral spacing of } \\
\text { the secondary suspension }\end{array}$ & $1930 / 1850$ \\
\hline
\end{tabular}

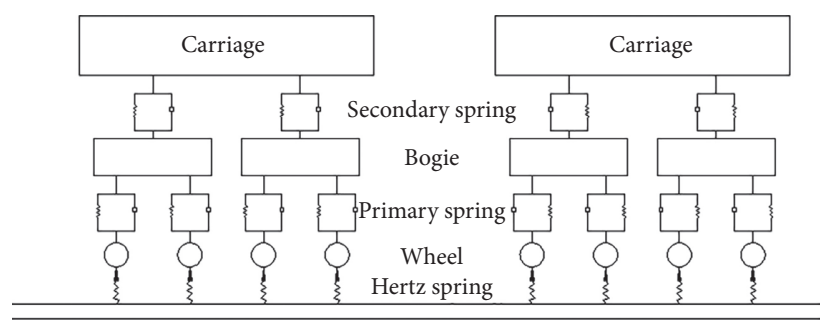

Figure 6: The simplified model of the metro train [25].

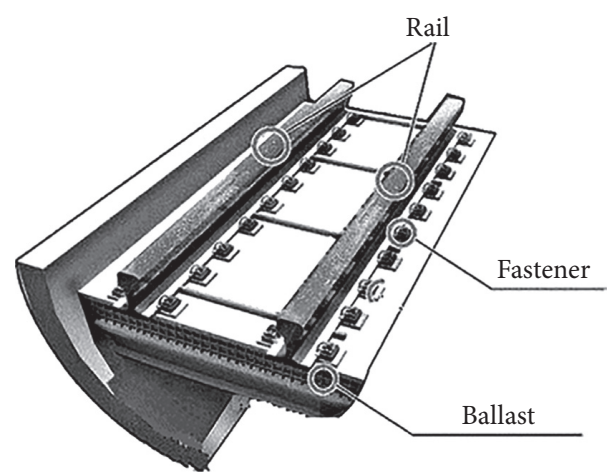

Figure 7: Track structure model [26].

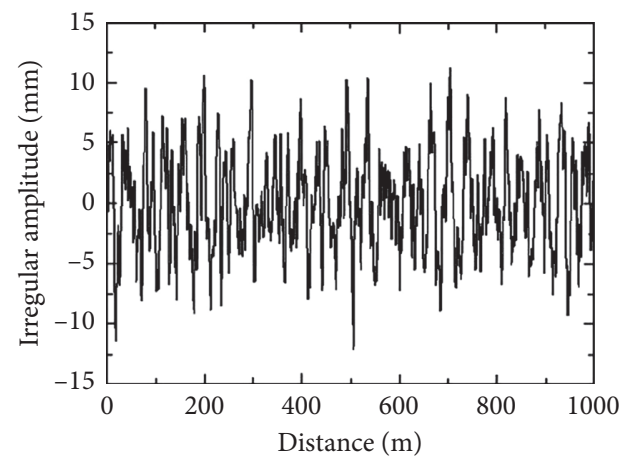

(a)

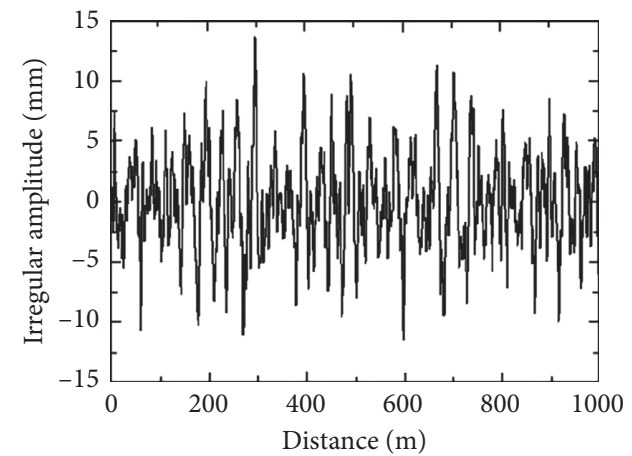

(b)

Figure 8: Continued. 


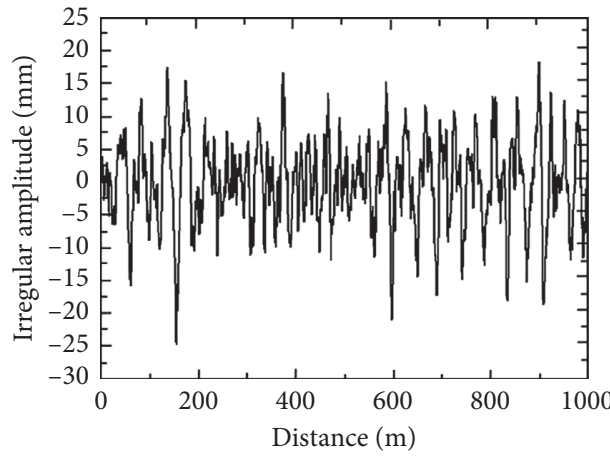

(c)

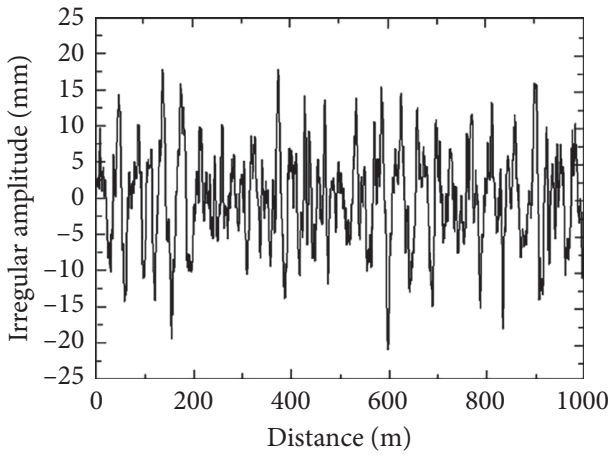

(d)

FIGURE 8: Irregularity spectrum of the grade five track of US. (a) Lateral irregularity of the left rail. (b) Transverse irregularity of the right rail. (c) Vertical irregularity of the left rail. (d) Vertical irregularity of the right rail.

TABLe 5: Passenger load and weight of the metro train.

\begin{tabular}{lccccccl}
\hline \multirow{2}{*}{ Load scenario } & \multicolumn{2}{c}{ Trailer car } & \multicolumn{2}{c}{ Motor car } & \multicolumn{2}{c}{ Train (3M2T) } & Remarks \\
& Number & $(t)$ & Number & $(t)$ & Number & $(t)$ & \\
\hline Empty scenario & 0 & 31 & 0 & 33 & 0 & 161 & \\
Personnel quota scenario & 230 & 44.8 & 250 & 48 & 1210 & 233.6 & The average weight of each passenger is set as 60 kg \\
Overcrowding scenario & 324 & 50.44 & 348 & 53.88 & 1692 & 262.52 & \\
\hline
\end{tabular}

TABLE 6: Train mechanical parameters.

\begin{tabular}{lcc}
\hline Parameters & Unit & Value \\
\hline Bogie (trailer/motor power car) & $\mathrm{t}$ & $5.4 / 6.5$ \\
Trailer body weight (empty scenario/personnel quota scenario/overcrowding scenario) & $\mathrm{t}$ & $22 / 35.8 / 41.44$ \\
Motor power car body weight (empty scenario/personnel quota scenario/overcrowding scenario) & $\mathrm{t}$ & $22.4 / 37.4 / 43.08$ \\
Rolling inertia of car body under overcrowding scenario (trailer/motor power car) & $\mathrm{t} \cdot \mathrm{m}^{2}$ & $33.956 / 35.3$ \\
Rotating inertia of body nodding under overcrowding scenario (trailer/motor power car) & $\mathrm{t} \cdot \mathrm{m}^{2}$ & $1391.814 / 1446.895$ \\
Moment of inertia of car body shaking head under overcrowding scenario (trailer/motor power car) & $\mathrm{t} \cdot \mathrm{m}^{2}$ & $1380.284 / 1434.91$ \\
Rolling inertia of car body under personnel quota scenario (trailer/motor power car) & $\mathrm{t} \cdot \mathrm{m}^{2}$ & $29.335 / 35.3$ \\
Rotating inertia of body nodding under personnel quota scenario (trailer/motor power car) & $\mathrm{t} \cdot \mathrm{m}^{2}$ & $1202.387 / 1446.895$ \\
Moment of inertia of car body shaking head under personnel quota scenario (trailer/motor power car) & $\mathrm{t} \cdot \mathrm{m}^{2}$ & $1192.428 / 1434.91$ \\
Frame weight (trailer/motor power car) & $\mathrm{t}$ & $2.56 / 3.42$ \\
Rolling inertia of frame (trailer/motor power car) & $\mathrm{t} \cdot \mathrm{m}^{2}$ & $1.05 / 1.43$ \\
Rotating inertia of nodding head of frame (trailer/motor power car) & $\mathrm{t} \cdot \mathrm{m}^{2}$ & $1.75 / 1.85$ \\
Rotating inertia of shaking head of frame (trailer/motor power car) & $\mathrm{t} \cdot \mathrm{m}^{2}$ & $1.98 / 2.95$ \\
Wheelset weight (trailer/motor power car) & $\mathrm{t}$ & $1.42 / 1.539$ \\
Rotating inertia of wheel-to-wheel roll (trailer/motor power car) & $\mathrm{t} \cdot \mathrm{m}^{2}$ & $0.739 / 0.801$ \\
Rotating inertia of wheelset nodding head (trailer/motor power car) & $\mathrm{t} \cdot \mathrm{m}^{2}$ & $0.096 / 0.104$ \\
Rotating inertia of wheelset shaking head (trailer/motor power car) & $\mathrm{t} \cdot \mathrm{m}^{2}$ & $0.751 / 0.814$ \\
Longitudinal stiffness of primary suspension (per axle box) (trailer/motor power car) & $\mathrm{MN} / \mathrm{m}$ & $6.6 / 10.6$ \\
Transverse stiffness of primary suspension (per axle box) (trailer/motor power car) & $\mathrm{MN} / \mathrm{m}$ & $5.2 / 7.8$ \\
Vertical stiffness of primary suspension (per axle box) & $\mathrm{MN} / \mathrm{m}$ & 1.7 \\
Longitudinal stiffness of secondary suspension & $\mathrm{MN} / \mathrm{m}$ & 0.21 \\
Lateral stiffness of secondary suspension & $\mathrm{MN} / \mathrm{m}$ & 0.21 \\
Vertical stiffness of secondary suspension & $\mathrm{MN} / \mathrm{m}$ & 0.45 \\
\hline
\end{tabular}

cushions, which can ensure the uniform elasticity and durable operation life of the track. In order to get more accurate results, the grid density at the important structure is increased. The model consists of 937 units and 8,165 nodes, as shown in Figure 5. The building material parameters are listed in Table 1 . The soil layers and tunnel parameters are listed in Table 2. And the fastener parameters are listed in Table 3.

3.3. Train Dynamic Load. Hitherto, tremendous progress has been achieved in the study of the Metro train load 


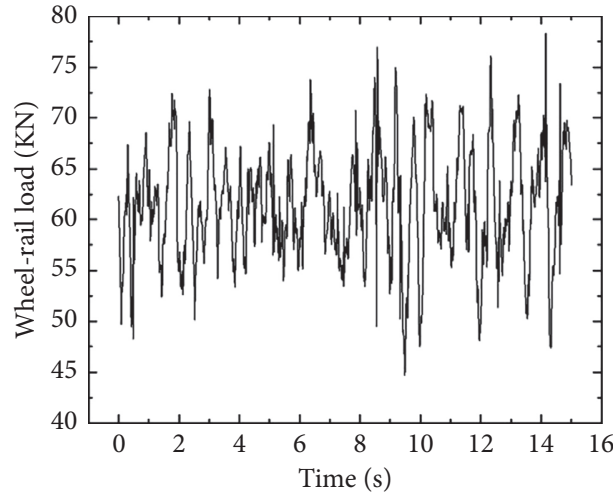

(a)

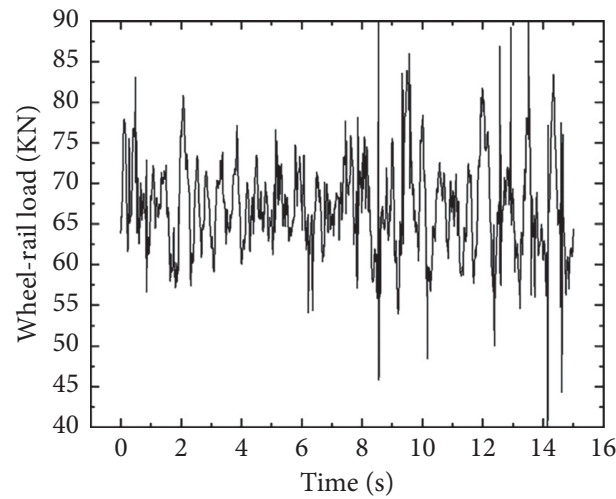

(c)

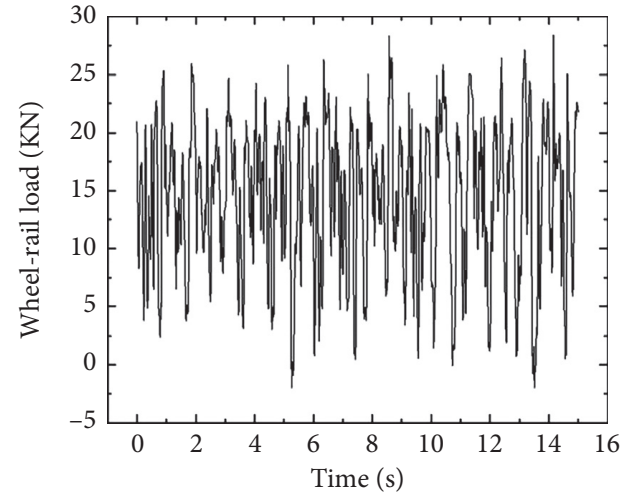

(b)

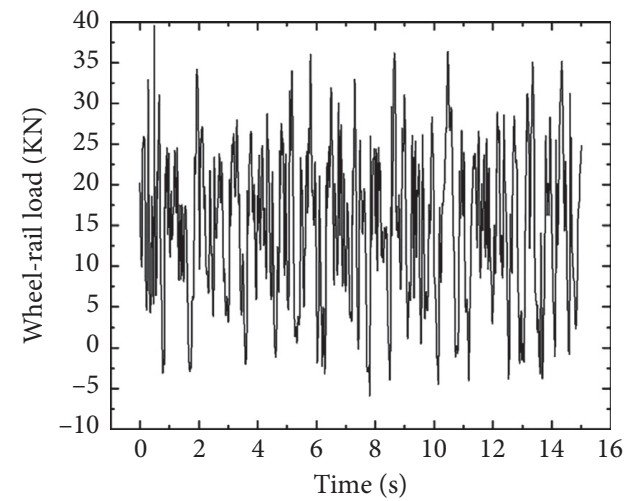

(d)

FIGURE 9: Wheel-rail force of the first wheel pair of an overcrowded-scenario trailer. (a) Vertical force of the inner rail. (b) Horizontal force of the internal rail. (c) Vertical force of the outer rail. (d) Horizontal force of the outer rail.

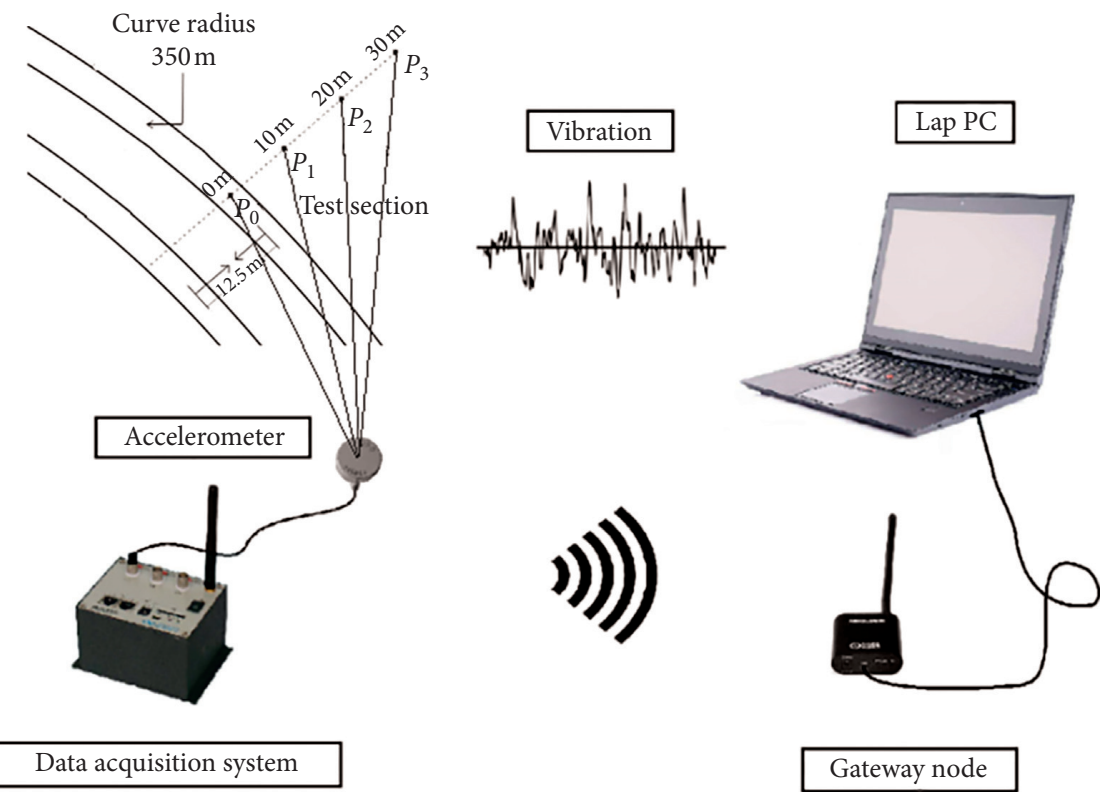

FIgURE 10: Illustration of the field test.

[29-32]. The primary methods to determine the dynamic load of the Metro are field measurements, numerical simulation, and empirical analysis. In this paper, a numerical model of the wheel-rail loads is demonstrated by using the multibody dynamics software, SIMPACK, taking the B-type vehicles, commonly used in urban rail transit in 
TABLe 7: Parameters of the piezoelectric accelerometer [33].

\begin{tabular}{lc}
\hline Parameters & Value \\
\hline Axial sensitivity $\left(20 \pm 5^{\circ} \mathrm{C}\right)$ & $\sim 50 \mathrm{mV} / \mathrm{ms}^{-2}$ \\
Measurement range (peak value) & $100 \mathrm{~ms}^{-2}$ \\
Maximum lateral sensitivity & $5 \%$ \\
Frequency response $(0.5 \mathrm{~dB})$ & $0.3 \sim 2500 \mathrm{~Hz}$ \\
Resonant frequency & $8000 \mathrm{~Hz}$ \\
Noise & $<0.08 \mathrm{~dB}$ \\
\hline
\end{tabular}

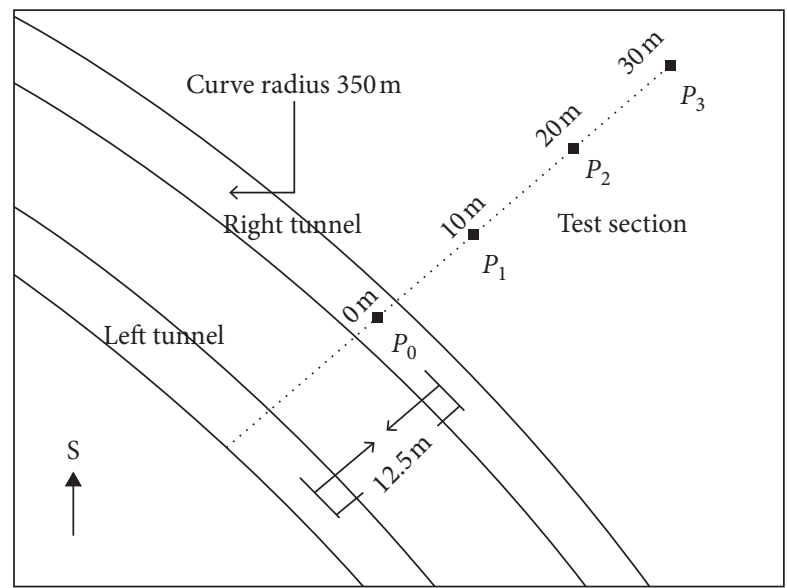

FIGURE 11: Layout of the measuring points.

China, as the study vehicle. The B-type vehicles have three motor (M) cars and two trailers (T), and the car sequence formation can be coded as + T-M-M-M-T+. The train speed is assumed to be $60 \mathrm{~km} / \mathrm{h}$, the radius of the plane curve $350 \mathrm{~m}$, the length of the transition curve $60 \mathrm{~m}$, the length of the circular curve $275 \mathrm{~m}$, and the height of the circular curve $120 \mathrm{~mm}$. Detailed structural parameters of the vehicle are shown in Table 4.

Figure 6 depicts a simplified Metro train model. A metro train is mainly composed of the body, bogie, wheel, and suspension system; the body and bogie are simulated by rigid body, and the suspension system is simulated by spring damping element. Figure 7 is the track structure model. The track structure is a layered structure with alternate elastic layer and rigid layer, mainly composed of the rail, fastener, sleeper, and track bed. The rail is simulated by beam element, which has the function of supporting and guiding. The elastic element is used to simulate the fastener; its elastic modulus is mainly provided by rubber and has high internal resistance; the function of the fastener is to fix the rail on the sleeper, keep the track gauge, and prevent the rail from moving vertically and horizontally. The sleeper and sleeper plate are simulated by beam element, which has the function of making the pressure of the train spread evenly to the foundation.

The random irregularity samples of the track are obtained by using the five-level track irregularity spectrum of the United States, as shown in Figure 8. The dynamic wheelrail forces of a single trailer car and a single motor car with different load scenarios are obtained, as shown in Table 5 . Train mechanical parameters are shown in Table 6.

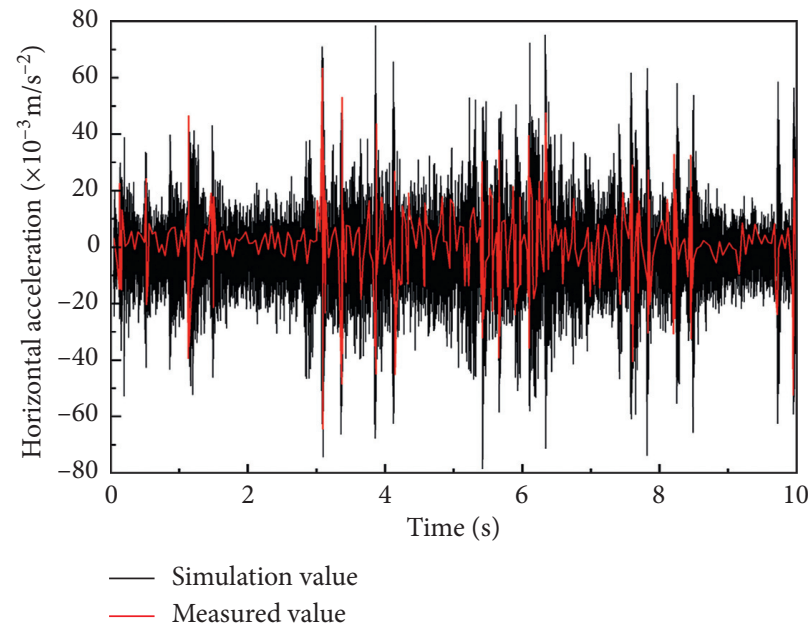

(a)

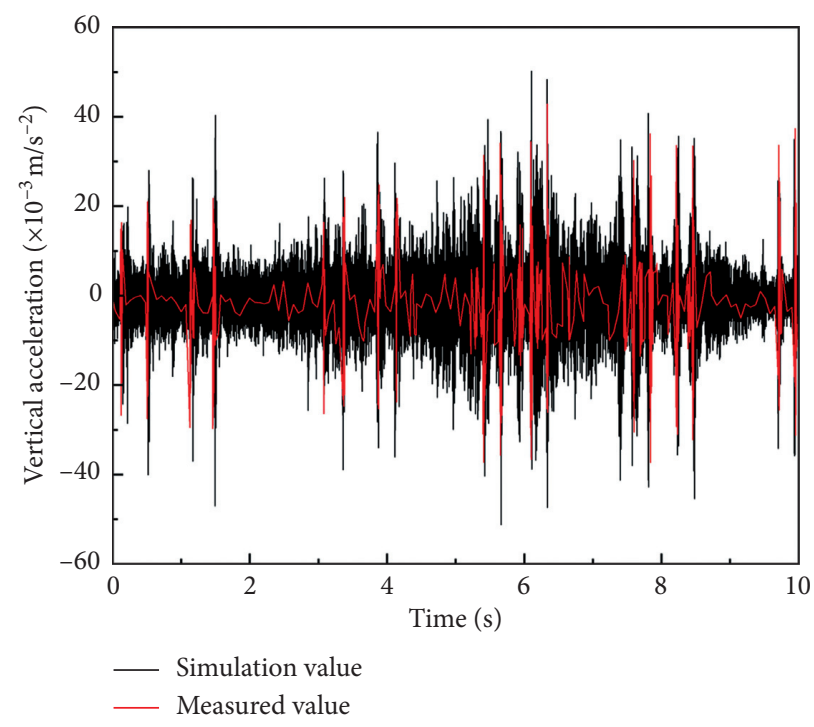

(b)

FIGURE 12: Comparison of measured and simulated acceleration spectra in time domain: (a) horizontal; (b) vertical.

Assuming that the dynamic wheel-rail forces of the vehicles with the same structure and different positions have only phase difference, the dynamic wheel-rail forces of all the motor vehicles and trailers are calculated according to the delay between the rear vehicle and the front vehicle (speed/workshop distance). For the conciseness, the scope of this paper only focuses on the wheelrail force of the first wheel pair of the overcrowdingscenario trailer, as shown in Figure 9. When the train dynamic load is applied to the FEM nodes of the tracktunnel-soil-building model as the load spectrum in the time domain, the vibration propagation in the underground structure can be calculated.

3.4. Model Verification. In order to effectively reduce the environmental background noise caused by the flow of people and ensure the accuracy of the data, the field 


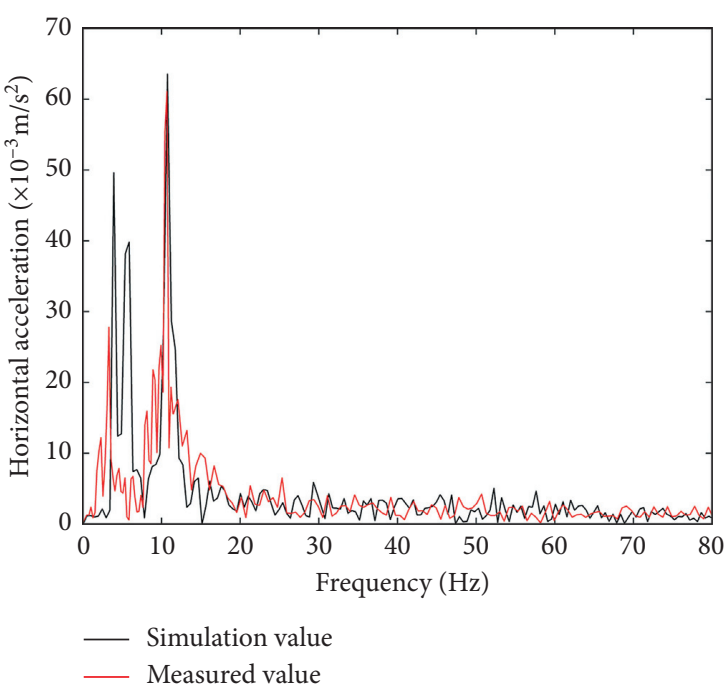

(a)

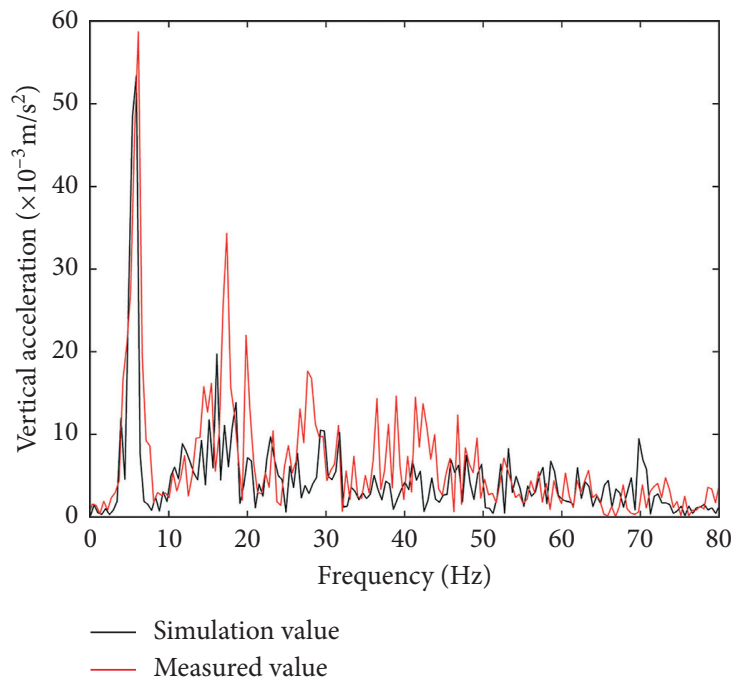

(b)

FIGURE 13: Comparison of measured and simulated acceleration spectra in frequency domain: (a) horizontal; (b) vertical.

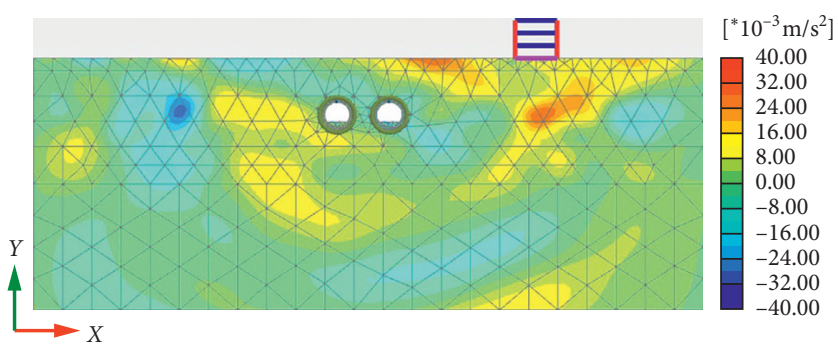

(a)

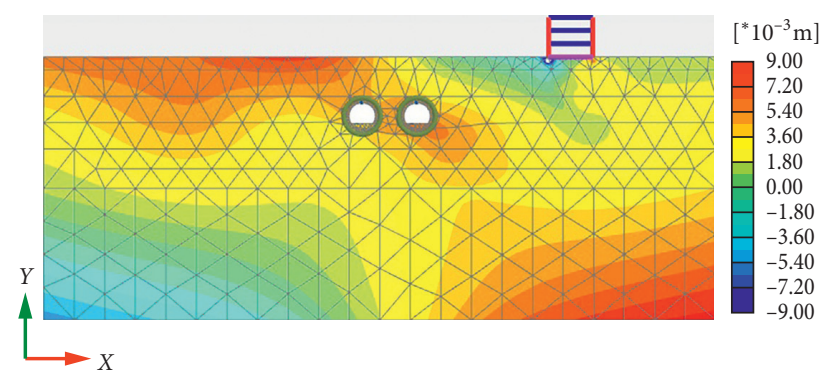

(c)

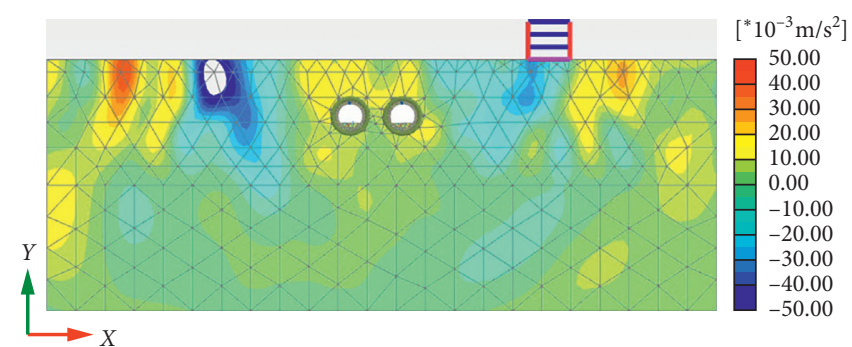

(b)

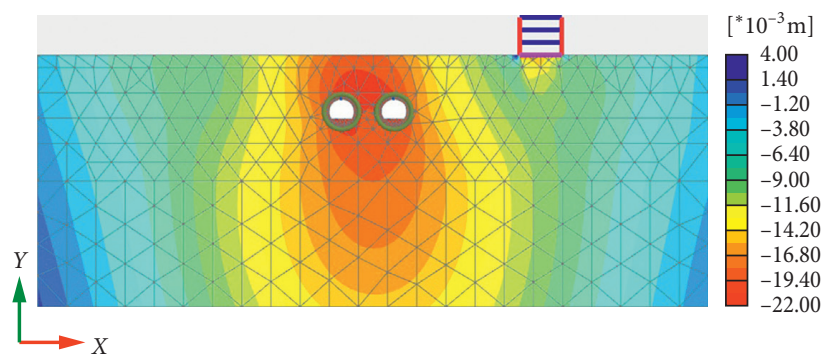

(d)

Figure 14: Acceleration and displacement contour plots of overcrowding. (a) Contour plot of the horizontal acceleration. (b) Contour plot of the vertical acceleration. (c) Contour plot of the horizontal displacement. (d) Contour plot of the vertical displacement.

measurements are arranged during the low passenger flow period of daytime subway operation, and each measuring point is tested many times. Four vibration receiver points, $P_{1}, P_{2}, P_{3}$, and $P_{4}$, are selected on the ground, located directly above the right tunnel in Figure 4 . The points are $0 \mathrm{~m}, 10 \mathrm{~m}$, $20 \mathrm{~m}$, and $30 \mathrm{~m}$, respectively, away from the center line of the right tunnel.

In this paper, the numerical model is validated through field measurements. The monitoring system consists of the accelerometers, data acquisition system, gateway node, and notebook computer. Figure 10 illustrates the configuration of the monitoring system. Data acquisition was conducted using a JM3870 wireless dynamic/static vibration analysis system, with a sampling frequency of $256 \mathrm{~Hz}$. The AI050 piezoelectric accelerometer is used, whose parameters are shown in Table 7 . The test area starts directly above the center line of the right tunnel, and a receiver point is arranged every $10 \mathrm{~m}$, with a total of four receiver points, as shown in Figure 11.

For the conciseness, only the measured and simulated acceleration curves in the both time and frequency domain of $P_{0}$ were listed. Figure 12 shows the measured and 


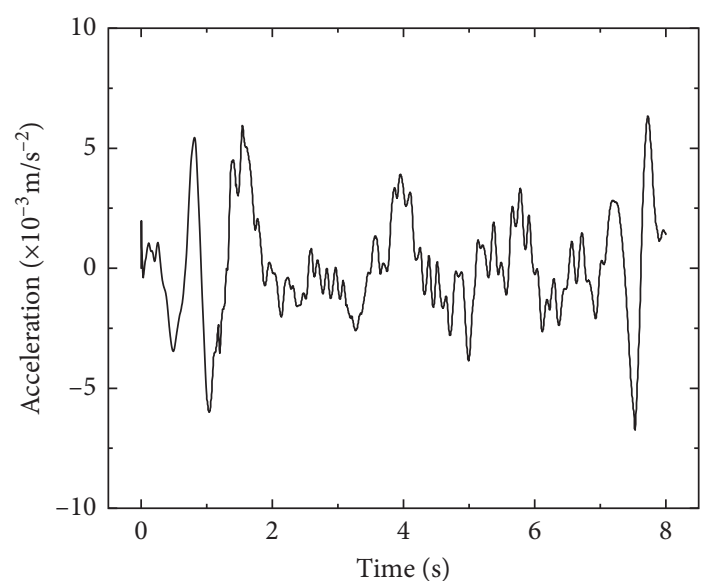

(a)

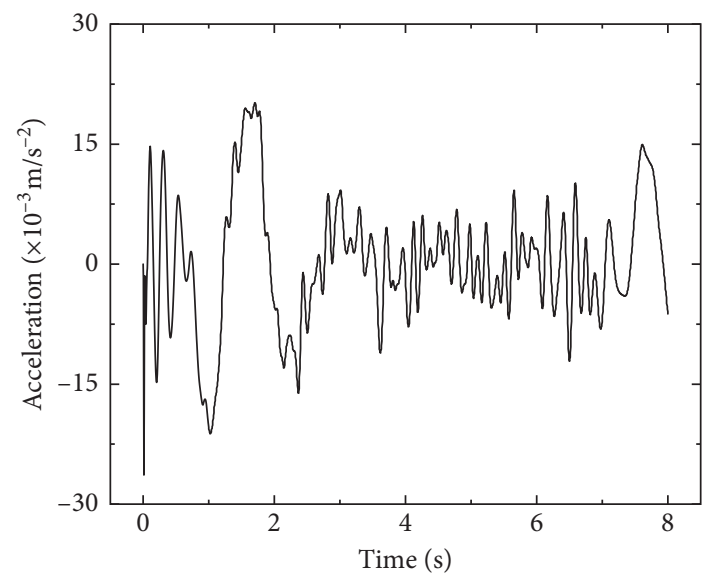

(c)

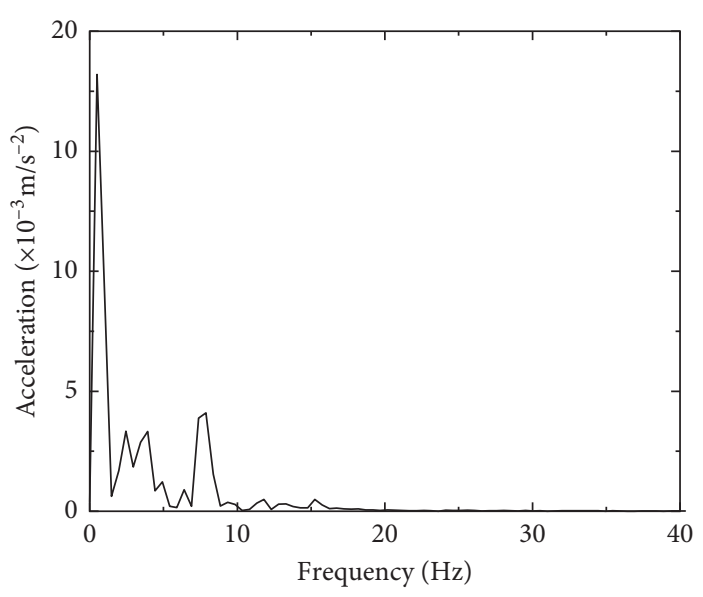

(b)

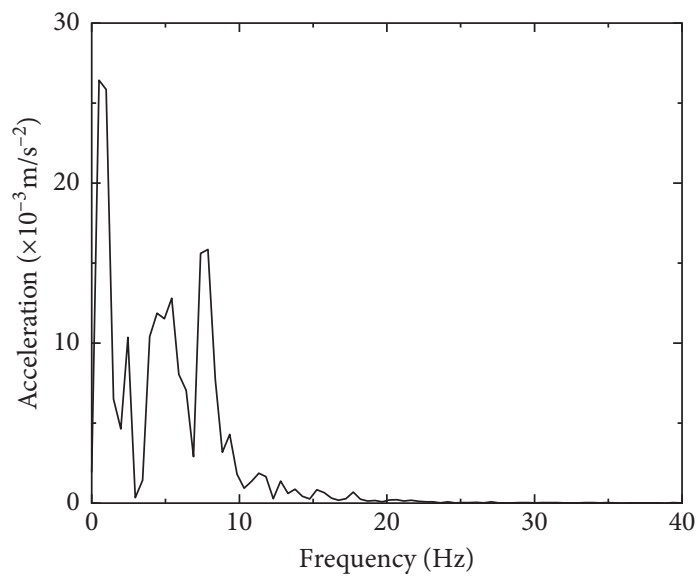

(d)

Figure 15: Acceleration of the floor 1 in time and frequency domain under overcrowding scenario. (a) Horizontal acceleration of the time domain. (b) Horizontal acceleration of the frequency domain. (c) Vertical acceleration of the time domain. (d) Vertical acceleration of the frequency domain.

simulated acceleration curves of $P_{0}$ in the time domain. Figure 13 shows the measured and simulated acceleration curves of $P_{0}$ in the frequency domain. Obviously, the general trend of the simulation and measurement is consistent. In Figure 12, the horizontal vibration acceleration is larger than that of the vertical vibration acceleration. In Figure 13, the measured acceleration frequency of $P_{0}$ mainly concentrates on $5-15 \mathrm{~Hz}$, while the simulated acceleration frequency concentrates on $4-18 \mathrm{~Hz}$, both in the low frequency band. The measured value is slightly larger than the simulated value, which may be effectuated by the external environmental impacts when the ground vibration is measured.

In horizontal and vertical directions, the error between the simulation and measurement is slight, suggesting that the numerical model is reasonable.

\section{Analysis of the Ambient Vibration Responses}

4.1. Ground Vibration Response. A total of six scenarios have been developed: Metro train meeting with overcrowding scenario, right train passing through floors with overcrowding scenario, left train passing through floors with overcrowding scenario, Metro train meeting with personnel quota scenario, right train passing through floors with personnel quota scenario, and left train passing through floors with personnel quota scenario.

The ground response of the Metro train meeting with overcrowding scenario is analyzed; Figure 14 shows the contour plots of the horizontal acceleration and displacement, vertical acceleration, and displacement of the simulated overcrowding scenario.

The displacement is related to the variation in the trend of the acceleration, so only the acceleration contour plot is presented here. The results show that the vibration acceleration generated by the Metro running on the curved segment has a certain amplification region in the soil layers. The acceleration does not decrease monotonously with the increase of the distance from the center line of the tunnel. The vertical acceleration tends to distribute symmetrically on both sides of the tunnel, and two amplification regions 


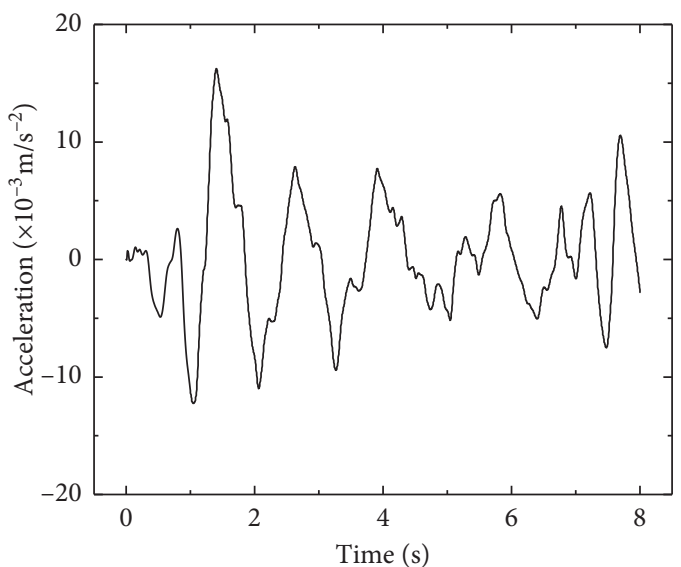

(a)

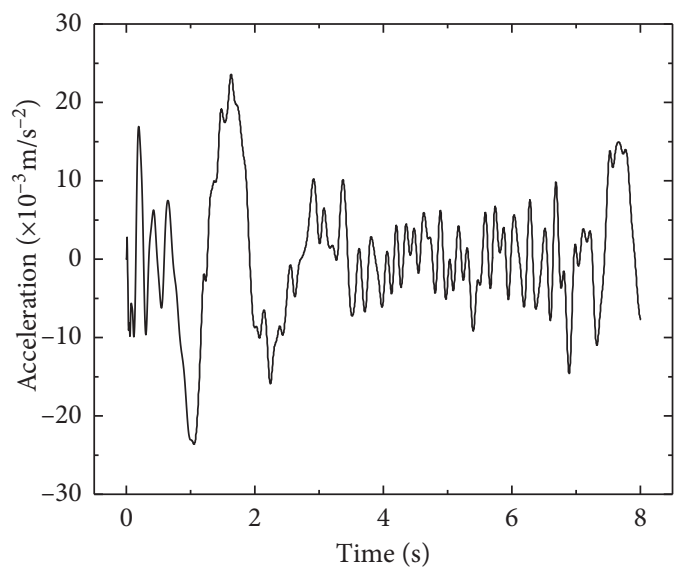

(c)

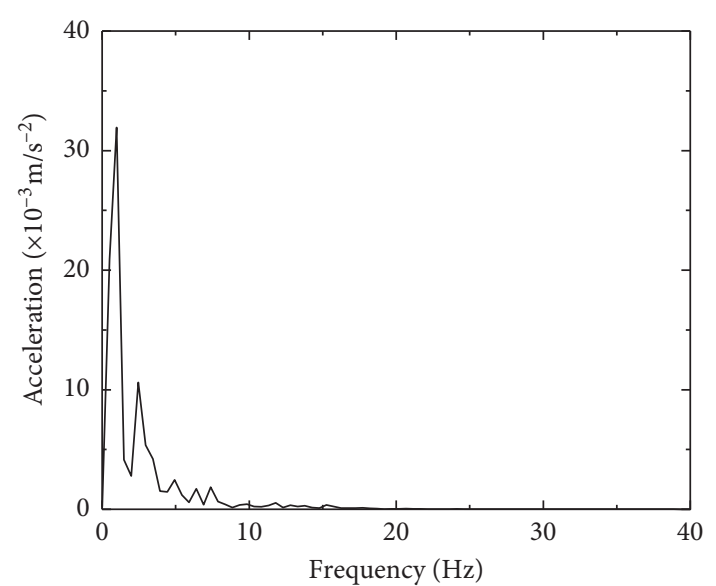

(b)

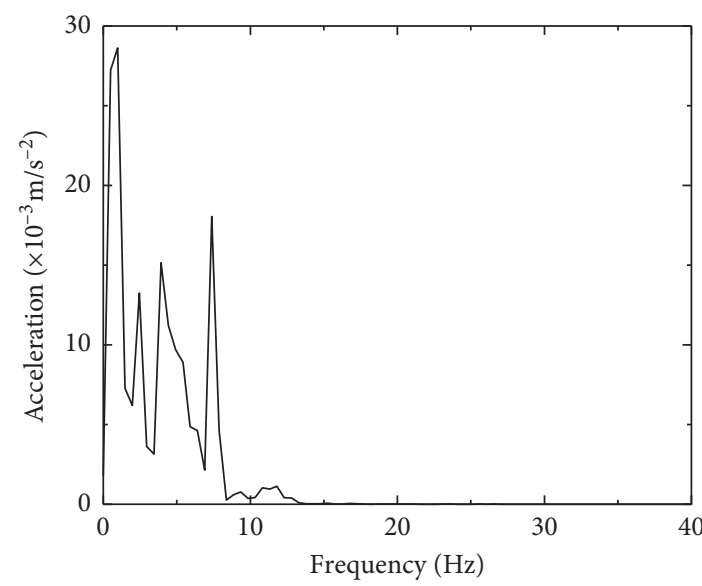

(d)

FIGURE 16: Acceleration of the floor 2 in time and frequency domain under overcrowding scenario. (a) Horizontal acceleration of the time domain. (b) Horizontal acceleration of the frequency domain. (c) Vertical acceleration of the time domain. (d) Vertical acceleration of the frequency domain.

exist. Horizontal vibration acceleration has a smaller magnification area in the soil layer on both sides of the building, directly below the building. Horizontal acceleration attenuates faster than vertical acceleration. Note that the absorption of the horizontal elastic waves by the soil layer is stronger than that of the vertical ones.

4.2. Building Vibration Response. Vibration pick-up points $A, B, C$, and $D$ are selected at the center of $1,2,3$, and 4 (roof) floors, respectively. These points are used to characterize the vibration response of the building with different scenarios, as shown in Figure 3. Herein, we only illustrate the acceleration time history and frequency spectrum, of each floor in the building, under the overcrowding scenario, as shown in Figures 15-18.

Note that the vibration of the building caused by Metro operation, in Figures 15-18, is mainly of low frequency within $10 \mathrm{~Hz}$ along both horizontal and vertical directions. The vertical acceleration is near $0.02 \mathrm{~m} / \mathrm{s}^{2}$, varying slightly with the height of the building. The horizontal acceleration increases significantly with the height of the building, from $0.005 \mathrm{~m} / \mathrm{s}^{2}$ to $0.03 \mathrm{~m} / \mathrm{s}^{2}$, nearly six times; the horizontal acceleration at the top of the building exceeds the vertical acceleration. Based on the fundamental frequencies ratio of the buildings and the foundation soils, the torsional or other modes of the building might be seen. Load frequency might create the resonance effects depending on overlapping degree of the frequencies of the load and structure. In this case, the load frequency focuses on $5 \mathrm{~Hz}$ and $10 \mathrm{~Hz}$ along the horizontal and 10 and $15 \mathrm{~Hz}$ along the vertical, while the first-order frequency of the building structure is only about $0.3 \mathrm{~Hz}$. Therefore, the Metro train load may not generate obvious resonance in the building structure. However, the facilities in the building, such as window glass, furniture, and garniture, which have higher nature frequencies, might resonate under the excitation of Metro train load. Moreover, load frequency exactly creates the secondary vibration upon the building. As a low-rise building, the secondary vibration of the adjacent building 


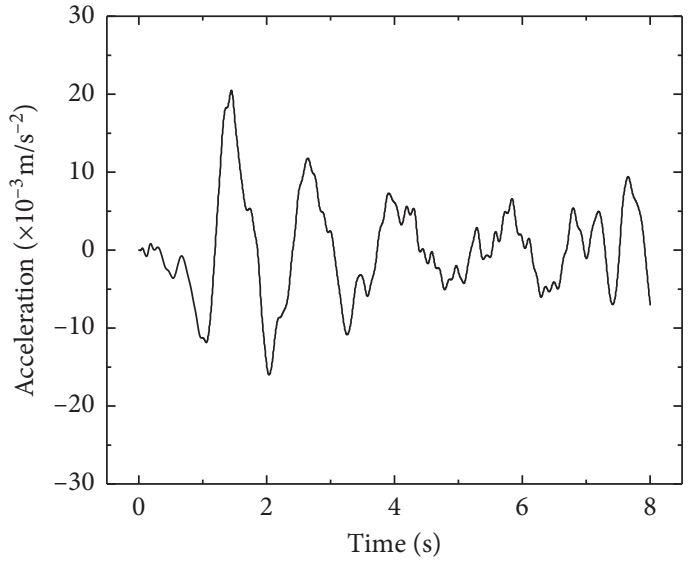

(a)

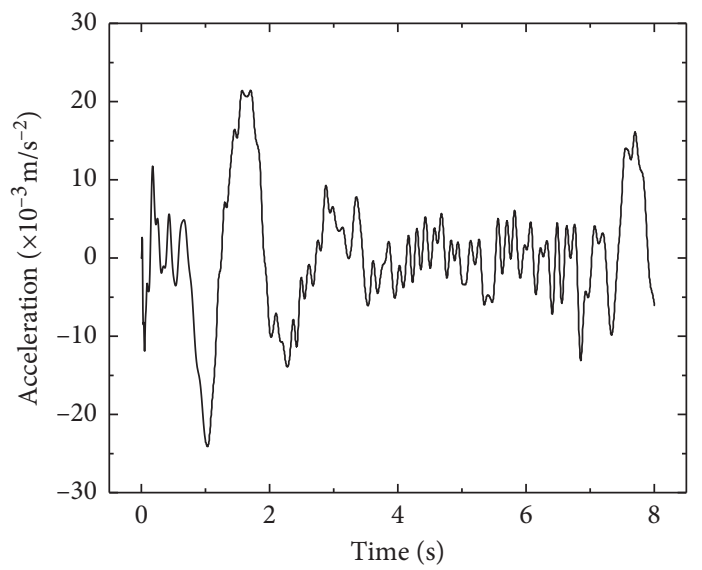

(c)

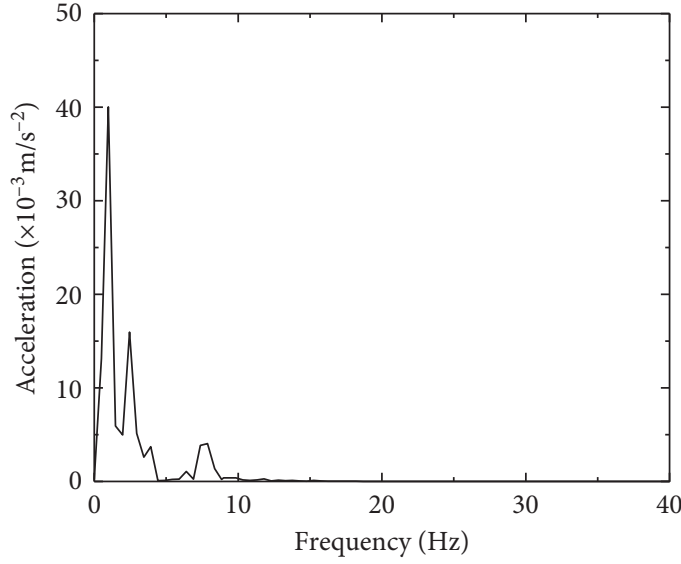

(b)

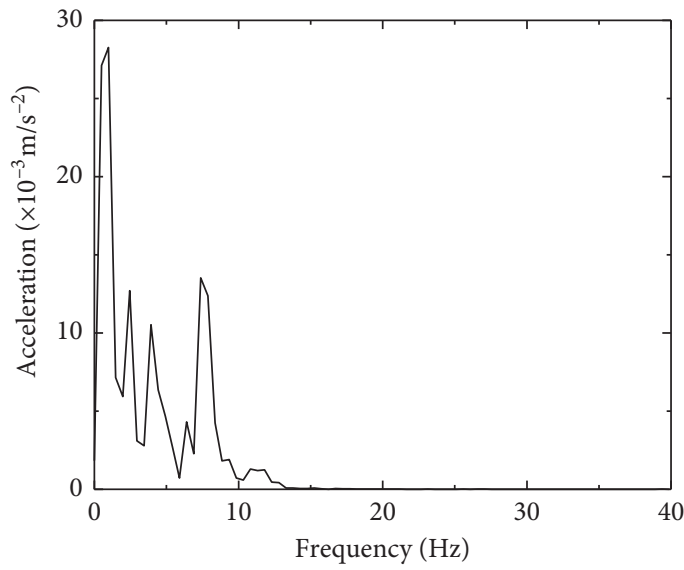

(d)

Figure 17: Acceleration of the floor 3 in time and frequency domain under overcrowding scenario. (a) Horizontal acceleration of the time domain. (b) Horizontal acceleration of the frequency domain. (c) Vertical acceleration of the time domain. (d) Vertical acceleration of the frequency domain.

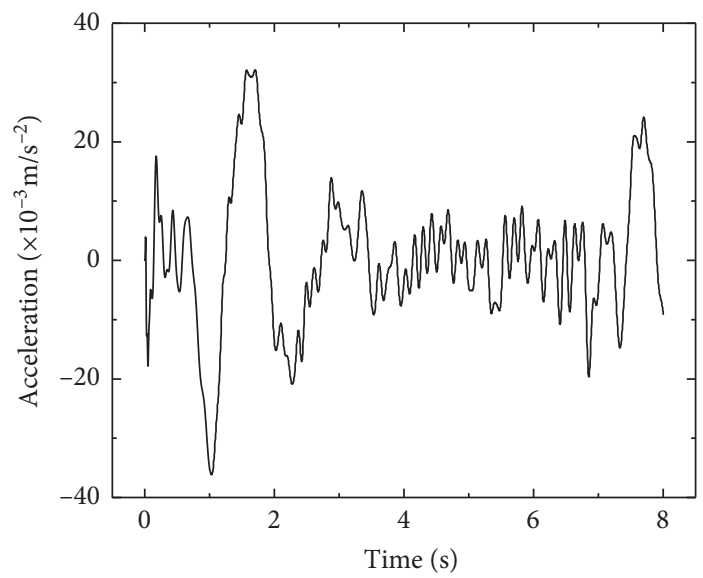

(a)

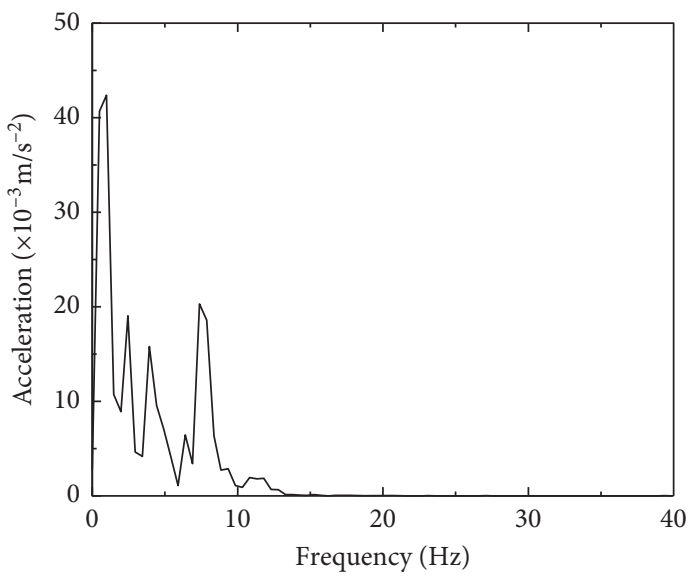

(b)

Figure 18: Continued. 


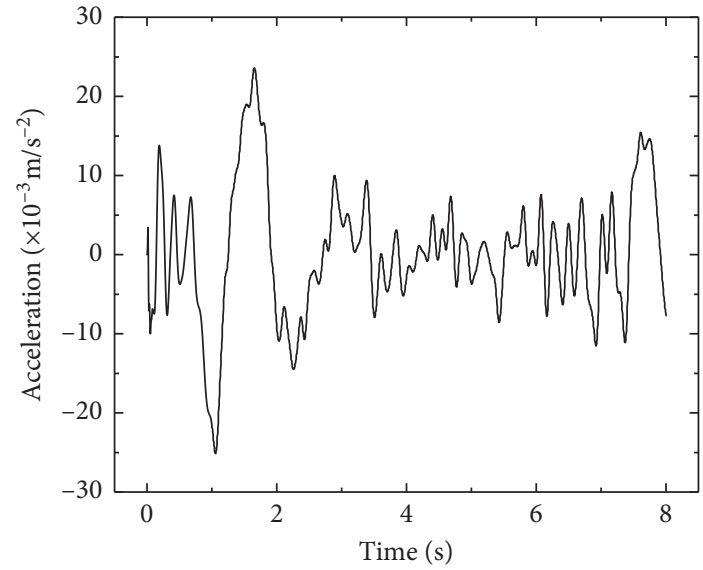

(c)

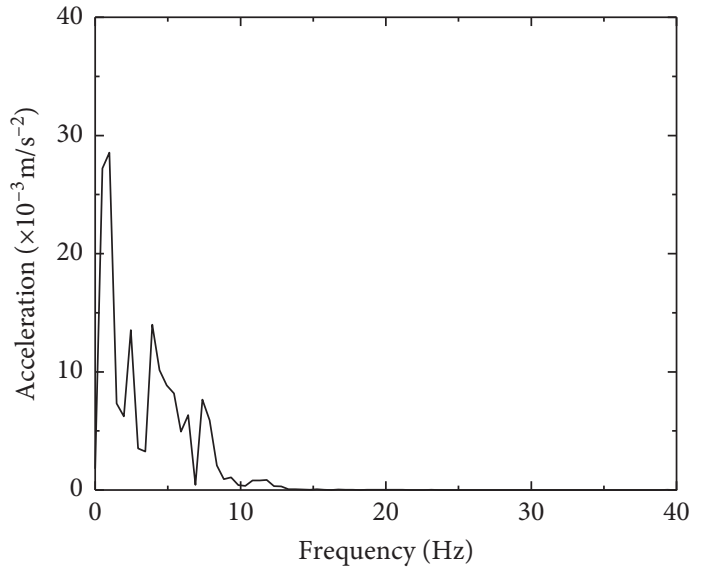

(d)

Figure 18: Acceleration of the floor 4 in time and frequency domain under overcrowding scenario. (a) Horizontal acceleration of the time domain. (b) Horizontal acceleration of the frequency domain. (c) Vertical acceleration of the time domain. (d) Vertical acceleration of the frequency domain.

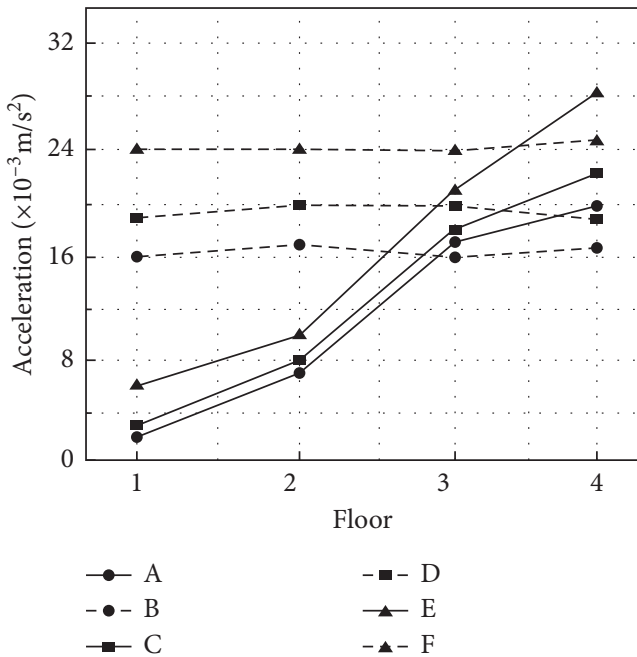

(a)

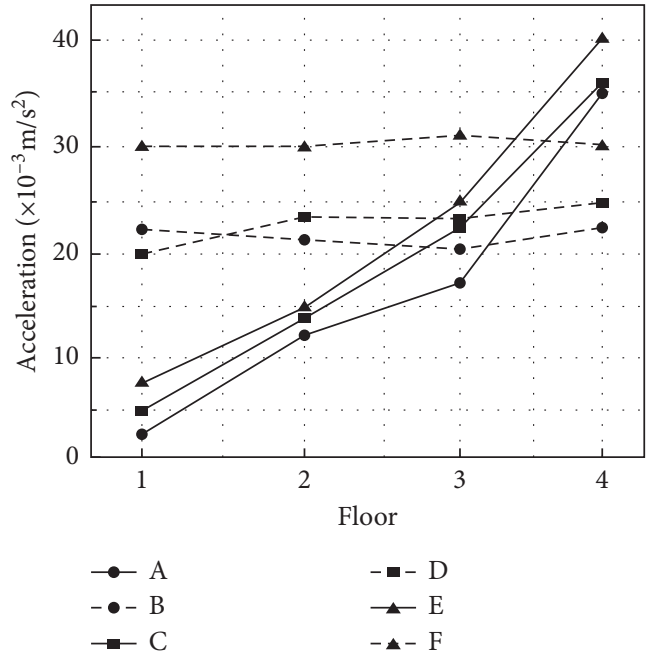

(b)

Figure 19: Acceleration peak of each floor under different scenarios. (a) Peak acceleration of the personnel quota scenario. (b) Peak acceleration of the overcrowding scenario. A: horizontal peak acceleration of the left train passing through building. B: vertical peak acceleration of the left train passing through building. C: horizontal peak acceleration of the right train passing through building. D: vertical peak acceleration of the right train passing through building. E: horizontal peak acceleration of the building during Metro meetings. F: vertical peak acceleration of the building during Metro meetings.

induced by the Metro operation does not attenuate with the height of the building, and the horizontal secondary vibration has a significant amplification effect upon the building.

4.3. Vibration Level of the Building. Figure 19 shows the peak acceleration, whereas Figure 20 shows the vibration level for each floor under different scenarios. Obviously, the change rules of the vibration level are consistent with that of the peak acceleration; hence, we analyze the vibration level to exemplify the change rules.
As seen from Figure 20, the horizontal vibration level increases gradually with the height of the building, increasing by $2-5 \mathrm{~dB}$ for each floor, while the vertical vibration level does not change significantly with the height of the building. By the mutual comparison among the floor vibration levels from scenarios (left, right, and meeting) of the same train with different load scenarios (personnel quota and overcrowding), we found that the overcrowding scenario of the same floor is $1-2 \mathrm{~dB}$ greater than that of the fixed one in both horizontal and vertical directions. The vibration level of the building on the same floor is $0.5-2 \mathrm{~dB}$ greater than that on the left. Compared with the single-track 


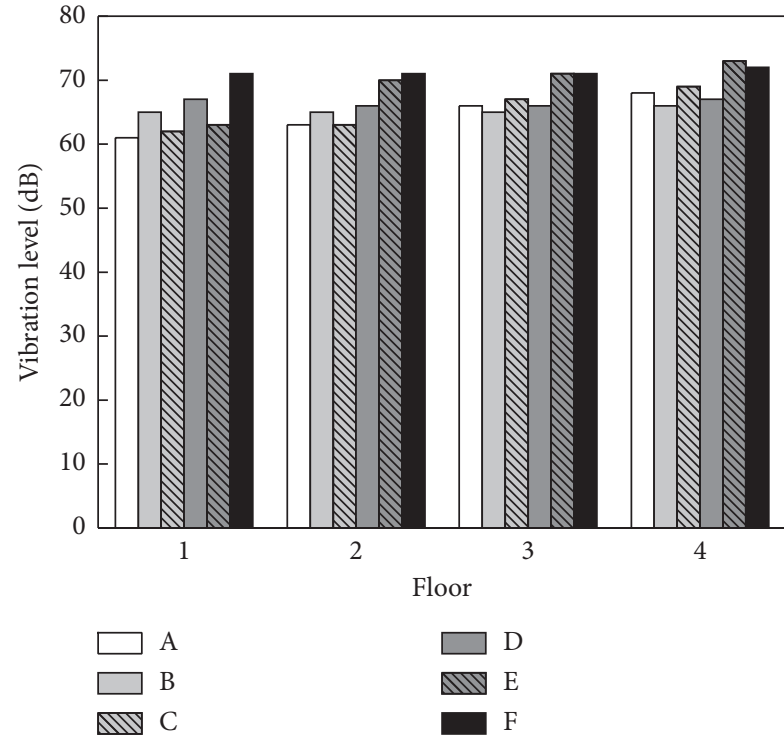

(a)

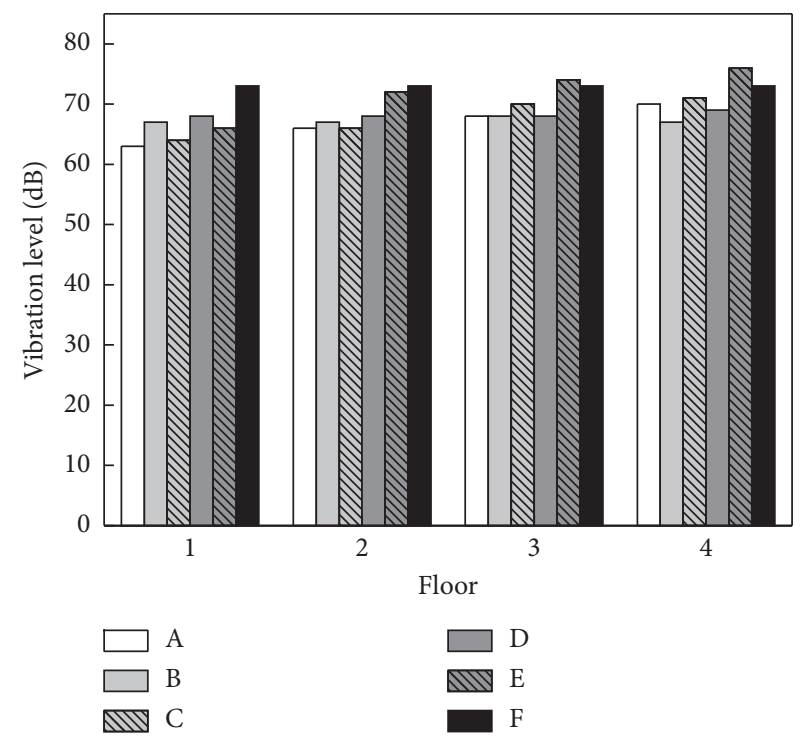

(b)

Figure 20: Vibration levels of each floor under different scenarios. (a) Vibration level of the personnel quota scenario. (b) Vibration level of the overcrowding scenario. A: horizontal vibration levels of the left train passing through building. B: vertical vibration levels of the left train passing through building. C: horizontal vibration levels of the right train passing through building. D: vertical vibration levels of the right train passing through building. E: horizontal vibration levels of the building during Metro meetings. F: vertical vibration levels of the building during Metro meetings.

scenario, the horizontal vibration level of each floor in the building is approximately $2-3 \mathrm{~dB}$ and the vertical vibration level is about $4-5 \mathrm{~dB}$.

\section{Conclusion}

In this paper, we used the mathematical equations of the wheel-rail creep force and vibration level formula and developed the wheel-rail force model of a B-type car passing through the curved segment based on the multibody dynamics. Taking a curved segment of Hangzhou Metro Line 1 as an example, a tunnel-soil-ground-building model has been demonstrated, and the ambient vibration response induced by the Metro trains on a curved segment with a radius of $350 \mathrm{~m}$ was analyzed. The conclusions are as follows:

(1) The external rail wheel-rail force is obviously higher than the internal rail wheel-rail force. The vertical force of the outer rail is generally $10-15 \mathrm{kN}$ higher than the vertical force of the inner rail, and the horizontal wheel-rail force of the outer rail is $5-10 \mathrm{kN}$ higher than the horizontal wheel-rail force of the inner rail. This is related to the centrifugal force produced by the train running in the curve segment. The horizontal wheel-rail force is close to half of the vertical force, so the horizontal effect cannot be ignored.

(2) The variation trend of the horizontal vibration acceleration with distance is larger, while the vertical vibration acceleration is gentler, and the peak value of the vertical vibration acceleration appears rebound at $20 \mathrm{~m}$. The horizontal vibration level above the tunnel is stronger than $90 \mathrm{~dB}$. With the increase of the distance, the vibration level gradually decreases to about $75 \mathrm{~dB}$ at $30 \mathrm{~m}$ away from the tunnel.

(3) The vibration yields an amplification area in soil layer. Vertical acceleration tends to distribute symmetrically on both sides of the tunnel, where two amplification regions occur. Horizontal acceleration yields smaller amplification regions on both sides of the building in the soil layers. Horizontal vibration attenuates faster than vertical vibration, so that the absorption of the horizontal vibration wave by soil layer is greater than the vertical vibration.

(4) The horizontal and vertical vibration induced by Metro building have a frequency lower than $10 \mathrm{~Hz}$. Vertical acceleration changes negligibly with the height of the building, about $0.02 \mathrm{~m} / \mathrm{s}^{2}$, whereas horizontal vibration acceleration increases significantly with the height of the building, from $0.005 \mathrm{~m} /$ $\mathrm{s}^{2}$ to $0.03 \mathrm{~m} / \mathrm{s}^{2}$. Furthermore, the horizontal acceleration at the top of the building exceeds the vertical acceleration. Note that the secondary vibration in the horizontal direction yields a significant amplification effect upon the building.

(5) The horizontal vibration level increases gradually, by $2-5 \mathrm{~dB}$, with the rise of each floor. The vertical vibration level changes negligibly with the height of the building. Under the overcrowding scenario, the vibration level of the same floor is 1-2 dB greater than that of the personnel quota scenario along both horizontal and vertical directions. As for the single-track scenario, the vibration level of the building on the same floor on the right line is 
0.5-2 dB larger than that on the left line. The vibration level of each floor of the building is $2-5 \mathrm{~dB}$ greater than that of the single line under the double-track scenario.

\section{Data Availability}

The data used to support the findings of this study are available from the corresponding author upon request.

\section{Conflicts of Interest}

The authors declare that there are no conflicts of interest regarding the publication of this paper.

\section{Acknowledgments}

This work was financially supported by the National Science Foundation of China (grant Nos. 40902076, 41722209), the Science Foundation of Jiangsu Province (grant No. BK20170574) and the Science \& Technology Program of Suzhou (grant Nos. SYG201611, SYG201713).

\section{References}

[1] F. Qin, X. Zhang, and Q. Zhou, "Evaluating the impact of organizational patterns on the efficiency of urban rail transit systems in China," Journal of Transport Geography, vol. 40, pp. 89-99, 2014.

[2] E. Peris, J. Woodcock, G. Sica, C. Sharp, A. T. Moorhouse, and D. C. Waddington, "Effect of situational, attitudinal and demographic factors on railway vibration annoyance in residential areas," The Journal of the Acoustical Society of America, vol. 135, no. 1, pp. 194-204, 2014.

[3] K. Sun and W. Zhang, "Combined annoyance assessment of subway train-induced structural vibration and ambient noise," Shock and Vibration, vol. 2016, Article ID 3028037, 8 pages, 2016.

[4] K. Sun, W. Zhang, H. Ding, R. E. Kim, and B. F. J. Spencer, "Autonomous evaluation of ambient vibration of underground spaces induced by adjacent subway trains using highsensitivity wireless smart sensors," Smart Structures and Systems, vol. 19, no. 1, pp. 1-10, 2017.

[5] K. Sun, W. Zhang, H. Ding, R. E. Kim, and B. F. Spencer, "Embedding human annoyance rate models in wireless smart sensors for assessing the influence of subway train-induced ambient vibration," Smart Materials and Structures, vol. 25, no. 10, p. 105023, 2016.

[6] P. Jik Lee and M. J. Griffin, "Combined effect of noise and vibration produced by high-speed trains on annoyance in buildings," The Journal of the Acoustical Society of America, vol. 133, no. 4, pp. 2126-2135, 2013.

[7] C.-d. Li, W. Zhang, H.-H. Zhu, P. Wang, J.-T. Ren, and B. F. Spencer, "Fast vibration characteristics analysis of an underwater shield tunnel using the accelerometer network enhanced by edge computing," Measurement, vol. 141, pp. 52-61, 2019.

[8] J. R. Hutchinson, "Shear coefficients for timoshenko beam theory," Journal of Applied Mechanics, vol. 68, no. 1, pp. 87-92, 2001.

[9] L. Auersch, "The excitation of ground vibration by rail traffic: theory of vehicle-track-soil interaction and measurements on high-speed lines," Journal of Sound and Vibration, vol. 284, no. 1-2, pp. 103-132, 2005.

[10] J. Shao, G. Xie, and L. Wang, "Leader-following formation control of multiple mobile vehicles," IET Control Theory \& Applications, vol. 1, no. 2, pp. 545-552, 2007.

[11] X. Sheng, C. J. C. Jones, and D. J. Thompson, "Modelling ground vibration from railways using wavenumber finite-and boundary-element methods," Proceedings of the Royal Society A: Mathematical, Physical and Engineering Science, vol. 461, pp. 2043-2070, 2005.

[12] S. Wolf, "Potential low frequency ground vibration," Journal of Sound and Vibration, vol. 267, no. 3, pp. 651-661, 2003.

[13] M. F. M. Hussein, H. E. M. Hunt, L. Rikse et al., "Using the PiP model for fast calculation of vibration from a railway tunnel in a multi-layered half-space," in Noise and Vibration Mitigation for Rail transportation systems, vol. 99, pp. 136-142, Springer, Berlin, Germany, 2008.

[14] X. Sheng, C. J. C. Jones, and D. J. Thompson, "Ground vibration generated by a harmonic load moving in a circular tunnel in a layered ground," Journal of Low Frequency Noise, Vibration and Active Control, vol. 22, no. 2, pp. 83-96, 2003.

[15] Y. B. Yang and L. C. Hsu, "A review of researches on groundborne vibrations due to moving trains via underground tunnels," Advances in Structural Engineering, vol. 9, no. 3, pp. 377-392, 2006.

[16] G. Volberg, "Propagation of ground vibrations near railway tracks," Journal of Sound and Vibration, vol. 87, no. 2, pp. 371-376, 1983.

[17] K. Hayakawa, M. Sawatake, R. Gotoh et al., "Reduction effect of ballast mats and EPS blocks on ground vibration caused by trains and its evaluation," in Proceedings of the INTER-NOISE and NOISE-CON Congress and Conference, vol. 1992, no. 2, pp. 593-596, New York, NY, USA, 1992.

[18] J. Melke and S. Kramer, "Diagnostic methods in the control of railway noise and vibration," Journal of Sound and Vibration, vol. 87, no. 2, pp. 377-386, 1983.

[19] J. Melke, "Noise and vibration from underground railway lines: proposals for a prediction procedure," Journal of Sound and Vibration, vol. 120, no. 2, pp. 391-406, 1988.

[20] H. Xia, N. Zhang, and Y. M. Cao, "Experimental study of traininduced vibrations of environments and buildings," Journal of Sound and Vibration, vol. 280, no. 3-5, pp. 1017-1029, 2005.

[21] Y. Okumura and K. Kuno, "Statistical analysis of field data of railway noise and vibration collected in an urban area," Applied Acoustics, vol. 33, no. 4, pp. 263-280, 1991.

[22] H. Zhang, W. Liu, K. Li et al., "Analytical solution for dynamic response of curved rail subjected to moving train," Journal of Vibroengineering, vol. 16, no. 4, pp. 2070-2081, 2014.

[23] X. Long, Q. Wei, Y. Wang et al., "Study on curve radius standard for linear metro," Journal of Beijing Jiaotong University, vol. 33, no. 4, pp. 110-114, 2009, in Chinese.

[24] Y.-H. Zhou, "Simulation of vibration effect and sensitivity analysis of soil parameters in automated metro station," Master's thesis, Nanjing University, Nanjing, China, 2017.

[25] W. Zhai, J. Gao, P. Liu, and K. Wang, "Reducing rail side wear on heavy-haul railway curves based on wheel-rail dynamic interaction," Vehicle System Dynamics, vol. 52, no. sup1, pp. 440-454, 2014.

[26] X. Jin, Z. Wen, K. Wang, and X. Xiao, "Effect of passenger car curving on rail corrugation at a curved track," Wear, vol. 260, no. 6, pp. 619-633, 2006.

[27] W. Zhai, K. Wang, and C. Cai, "Fundamentals of vehicle-track coupled dynamics," Vehicle System Dynamics, vol. 47, no. 11, pp. 1349-1376, 2009. 
[28] Z. Nan, M. Kai, T. Shaoxue, L. Ting, and C. Binlei, "Comfort degree analysis on metro vibration isolation based on $1 / 3$ times frequency course SPECTRUM," in Proceedings of the 2011 International Conference on Electric Technology and Civil Engineering (ICETCE) IEEE, Lushan, China, April 2011.

[29] Y. B. Yang, H. H. Hung, and D. W. Chang, "Train-induced wave propagation in layered soils using finite/infinite element simulation," Soil Dynamics and Earthquake Engineering, vol. 23, no. 4, pp. 263-278, 2003.

[30] H. Takemiya, "Simulation of track-ground vibrations due to a high-speed train: the case of X-2000 at Ledsgard," Journal of Sound and Vibration, vol. 261, no. 3, pp. 503-526, 2003.

[31] J. C. O. Nielsen and A. Igeland, "Vertical dynamic interaction between train and track influence of wheel and track imperfections," Journal of Sound and Vibration, vol. 187, no. 5, pp. 825-839, 1995.

[32] J. X. Lai, K. Y. Wang, and J. L. Qiu, "Vibration response characteristics of the cross tunnel structure," Shock and Vibration, vol. 2016, Article ID 9524206, 16 pages, 2016.

[33] B. Pan, W. Zhang, J.-Q. Cao et al., "Dynamic responses of soils around a one-hole double-track tunnel with the Metro trainmeeting," Shock and Vibration, vol. 2020, Article ID 1782803, 16 pages, 2020. 